\title{
Theoretical and Kinetic Tools for Selecting Effective Antioxidants: Application to the Protection of Omega-3 Oils with Natural and Synthetic Phenols
}

\author{
Romain Guitard, Véronique Nardello-Rataj * and Jean-Marie Aubry * \\ Univ. Lille, CNRS, Centrale Lille, ENSCL, Univ. Artois, UMR 8181-UCCS-Unité de Catalyse et Chimie du Solide, \\ F-59000 Lille, France; romain.guitard@live.fr \\ * Correspondence: veronique.rataj@univ-lille1.fr (V.N.-R.); jean-marie.aubry@univ-lille1.fr (J.-M.A.); \\ Tel.: +33-3-2033-6369 (V.N.-R.); +33-3-2033-6364 (J.-M.A.)
}

Academic Editor: Maria Laura Colombo

Received: 3 June 2016; Accepted: 21 July 2016; Published: 29 July 2016

\begin{abstract}
Radical-scavenging antioxidants play crucial roles in the protection of unsaturated oils against autoxidation and, especially, edible oils rich in omega-3 because of their high sensitivity to oxygen. Two complementary tools are employed to select, among a large set of natural and synthetic phenols, the most promising antioxidants. On the one hand, density functional theory (DFT) calculations provide bond dissociation enthalpies (BDEs) of 70 natural (i.e., tocopherols, hydroxybenzoic and cinnamic acids, flavonoids, stilbenes, lignans, and coumarins) and synthetic (i.e., 2,6-di-tert-butyl-4-methylphenol (BHT), 3-tert-butyl-4-hydroxyanisol (BHA), and tert-butylhydroquinone (TBHQ)) phenols. These BDEs are discussed on the basis of structure-activity relationships with regard to their potential antioxidant activities. On the other hand, the kinetic rate constants and number of hydrogen atoms released per phenol molecule are measured by monitoring the reaction of phenols with 2,2-diphenyl-1-picrylhydrazyl (DPPH ${ }^{\bullet}$ ) radical. The comparison of the results obtained with these two complementary methods allows highlighting the most promising antioxidants. Finally, the antioxidant effectiveness of the best candidates is assessed by following the absorption of oxygen by methyl esters of linseed oil containing $0.5 \mathrm{mmol} \mathrm{L}^{-1}$ of antioxidant and warmed at $90^{\circ} \mathrm{C}$ under oxygen atmosphere. Under these conditions, some natural phenols namely epigallocatechin gallate, myricetin, rosmarinic and carnosic acids were found to be more effective antioxidants than $\alpha$-tocopherol.
\end{abstract}

Keywords: natural and synthetic phenols; antioxidant; bond dissociation enthalpy (BDE); 2,2-diphenyl-1-picrylhydrazyl ( $\left.\mathrm{DPPH}^{\bullet}\right)$; omega-3 fatty acid methyl esters (FAMEs); linseed oil; autoxidation; stoichiometric number

\section{Introduction}

Omega-3 essential fatty acids have drawn attention of scientists for many years and studies have multiplied in recent decades, highlighting their virtues and mandatory character to the proper functioning of human bodies [1,2]. Nevertheless, due to their large number of unsaturations, omega-3 oils are highly oxidizable. This process plays an important role in the degradation of the organoleptic properties of food. All lipids containing unsaturated fatty acids such as vegetable oils, fish oils, animal fats, cell membranes and lipoproteins are concerned with lipid peroxidation. In recent decades, mechanistic studies of lipid peroxidation have known a renewed interest because of their implication in the field of nutrition.

Unsaturated lipids (LH) are prone to autoxidation, which takes place in three main steps. The first one is the initiation step which consists of the loss of a hydrogen atom triggered by metal traces, light or heat (Equation (1)). The resulting lipid radical $\left(\mathrm{L}^{\bullet}\right)$ reacts with fundamental oxygen 
$\left({ }^{3} \mathrm{O}_{2}\right)$ in a second step to form a peroxyl radical (LOO•) (Equation (2)). During the propagation stage, $\mathrm{LOO}^{\bullet}$ reacts with $\mathrm{LH}$ to form fatty acid hydroperoxides ( $\mathrm{LOOH}$ ) which are primary oxidation products (Equation (3)). In a third step, i.e., the termination step, two radicals react together to form non-radical products (Equations (4)-(6)) [3,4]. Hydroperoxides are unstable compounds that lead to alcoxyl (LO•) and peroxyl $\left(\mathrm{LOO}^{\bullet}\right)$ radicals which further form other oxidized products such as alcohols, aldehydes and ketones. One possible decomposition of lipid hydroperoxides is known as the Russel mechanism in which the combination of two peroxyl radicals LOO ${ }^{\bullet}$ provides a ketone $\mathrm{L}(\mathrm{O})$, an alcohol $\mathrm{LOH}$ and singlet molecular oxygen ${ }^{1} \mathrm{O}_{2}$ which can take place in biological systems (Equation (4)). Cyclisation mechanisms can also be involved in the formation of cyclic peroxides [5].

Initiation

$$
\mathrm{LH} \stackrel{\text { Initiator }}{\longrightarrow} \mathrm{L}^{\bullet}+\mathrm{H}^{\bullet}
$$

Propagation

$$
\begin{gathered}
\mathrm{L}^{\bullet}+{ }^{3} \mathrm{O}_{2} \longrightarrow \mathrm{LOO}^{\bullet} \\
\mathrm{LOO}^{\bullet}+\mathrm{LH} \longrightarrow \mathrm{LOOH}+\mathrm{L}^{\bullet}
\end{gathered}
$$

Termination

$$
\begin{gathered}
\mathrm{LOO}^{\bullet}+\mathrm{LOO}^{\bullet} \longrightarrow \mathrm{L}(\mathrm{O})+\mathrm{LOH}+{ }^{1} \mathrm{O}_{2} \\
\mathrm{LOO}^{\bullet}+\mathrm{L} \stackrel{\longrightarrow}{\longrightarrow} \mathrm{LOOL} \\
\mathrm{L}^{\bullet}+\mathrm{L}^{\bullet} \longrightarrow \mathrm{LL}
\end{gathered}
$$

In order to reduce the damages of these free radicals on food and biological systems, scientists are searching effective and non-toxic antioxidants [6]. Different factors influence the antioxidant power of phenols [7]: (i) Low value of Bond Dissociation Enthalpy (BDE) of the phenolic bond favors the transfer of the phenolic hydrogen to free radicals (i.e., $\mathrm{R}^{\bullet}, \mathrm{RO}^{\bullet}$ and $\mathrm{ROO}^{\bullet}$ ) [8-13]; (ii) High value of ionization potential (IP) avoids the transfer of electron from phenols to oxygen. Consequently, the pro-oxidant potential of the antioxidant is reduced [7,11,14-17]; (iii) high solubility of the phenol into the protected medium improves the antioxidant power [18,19].

There are numerous experimental and theoretical investigations dealing with bond dissociation enthalpies (BDEs) of antioxidants [14,20-23]. Nevertheless, they are sometimes inconsistent with each other. Indeed, such data are basis set and solvent dependent. It is then crucial to have a reliable method that can accurately predict the BDEs of a large scope of phenols and build a predictive scale of their antioxidant power, supported by experimental data.

In this paper, we determine the BDEs of 70 natural (i.e., tocopherols, derivatives of hydroxybenzoic and cinnamic acids, flavonols, flavones, flavanonols, flavanones, isoflavones, flavanols, stilbenes, lignans, and coumarins) and synthetic (i.e., 2,6-di-tert-butyl-4-methylphenol (BHT), 3-tert-butyl-4-hydroxyanisol (BHA), tert-butylhydroquinone (TBHQ), and propyl gallate (PG)) antioxidants by density functional theory (DFT) calculation. The method is referred to as B3LYP/6-311++G(2d,2p)//B3LYP/6-311G(d,p) and allows the calculation of accurate BDEs in relative short time. On the other hand, kinetic rate constants and number of hydrogen atoms released per molecule of phenol have also been measured by monitoring the reaction of phenols with $\mathrm{DPPH}^{\bullet}$ radical. The comparison of the results obtained with those two complementary methods allows highlighting the most promising antioxidants. Finally, the antioxidant effectiveness of the best candidates has been assessed under more realistic conditions by following during the oxidation process the absorption of oxygen by fatty acid methyl esters (FAMEs) of linseed oil containing $0.5 \mathrm{mmol} \cdot \mathrm{L}^{-1}$ of antioxidant.

\section{Results}

\subsection{Bond Dissociation Enthalpies (BDE) of 70 Phenolic Antioxidants}

All of the (poly)phenols studied in this work are gathered by families in Table 1 and are classified from the lowest BDE to the highest BDE. The antioxidant power of 10 synthetic antioxidants, 
four tocopherols, eight hydroxybenzoic and eight hydroxycinnamic acids derivatives, 13 flavonols, two flavones, two flavanonols, four flavanones, three isoflavones, three catechins, two stilbenes, eugenol and isoeugenol, three phenols found in olive oil, one lignan, three coumarins, carnosic acid and carnosol are studied by DFT calculation. BDEs of all the $\mathrm{O}-\mathrm{H}$ sites for each molecule have been calculated and results are described in supplementary materials (Table S1).

Table 1. Names and numbers of the polyphenols studied in this work.

\begin{tabular}{|c|c|c|c|c|c|}
\hline $\mathbf{N}^{\circ}$ & Name & $\mathbf{N}^{\circ}$ & Name & $\mathbf{N}^{\circ}$ & Name \\
\hline & Synthetic phenols & & Flavonols & & Catechins \\
\hline 1 & 5-Tert-butylpyrogallol & 31 & Gossypetin & 55 & Epigallocatechin gallate \\
\hline 2 & Pyrogallol & 32 & Myricetin & 56 & Gallocatechin \\
\hline 3 & Hydroxyquinol & 33 & Azaleatin & 57 & Catechin \\
\hline 4 & Propyl gallate & 34 & Quercetin & & \\
\hline 5 & BHA & 35 & Fisetin & & Stilbenes \\
\hline 6 & 4-Tert-butylcatechol & 36 & Laricitrin & 58 & Piceatannol \\
\hline 7 & BHT & 37 & Syringetin & 59 & Resveratrol \\
\hline 8 & TBHQ & 38 & Rhamnazin & & \\
\hline 9 & $o$-Tert-butyl- $p$-cresol & 39 & Kaempferide & & Aromatic phenols \\
\hline \multirow[t]{3}{*}{10} & Phloroglucinol & 40 & Isorhamnetin & 60 & Isoeugenol \\
\hline & & 41 & Morin & 61 & Eugenol \\
\hline & Tocopherols & 42 & Kaempferol & & \\
\hline 11 & $\alpha$-Tocopherol & 43 & Galagin & & Phenols from olive oil \\
\hline 12 & $\beta$-Tocopherol & & & 62 & Hydroxytyrosol \\
\hline 13 & $\gamma$-Tocopherol & & Flavones & 63 & Catechol \\
\hline \multirow[t]{3}{*}{14} & $\delta$-Tocopherol & 44 & Luteolin & 64 & Tyrosol \\
\hline & & 45 & Apigenin & & \\
\hline & Hydroxybenzoic acids & & & & Lignans \\
\hline 15 & Gallic acid & & Flavanonols & 65 & Sesamol \\
\hline 16 & Protocatechuic acid & 46 & Taxifolin & & \\
\hline 17 & Syringic acid & 47 & Aromadedrin & & Coumarins \\
\hline 18 & Ellagic acid & & & 66 & Methylesculetin \\
\hline 19 & Gentisic acid & & Flavanones & 67 & Aesculetin \\
\hline 20 & Vanillic acid & 48 & Eriodictyol & 68 & Nordalbergin \\
\hline 21 & PHBA & 49 & Homoeriodictyol & & \\
\hline \multirow[t]{3}{*}{22} & Salicylic acid & 50 & Hesperetin & & Carnosic acid derivatives \\
\hline & & 51 & Naringenin & 69 & Carnosol \\
\hline & Hydroxycinnamic acids & & & 70 & Carnosic acid \\
\hline 23 & Rosmarinic acid & & Isoflavones & & \\
\hline 24 & Caffeic acid & 52 & Glycitein & & \\
\hline 25 & Chlorogenic acid & 53 & Genistein & & \\
\hline 26 & Sinapic acid & 54 & Daidzein & & \\
\hline 27 & Ferulic acid & & & & \\
\hline 28 & $o$-Coumaric acid & & & & \\
\hline 29 & $p$-Coumaric acid & & & & \\
\hline 30 & $m$-Coumaric acid & & & & \\
\hline
\end{tabular}

Table 2 summarizes the calculated BDEs by the B3LYP/6-311++G(2d,2p)/ /B3LYP/6-311G $(d, p)$ method for the 70 phenols. Literature values are given in bracket and compared with our own values in supplementary materials (Figures S2-S4).

Table 2. Bond dissociation enthalpies (BDEs) for the phenolic antioxidants studied (1-70).

\begin{tabular}{|c|c|c|c|c|c|c|}
\hline \multicolumn{7}{|c|}{ Synthetic phenolic antioxidants } \\
\hline \\
\hline $\mathbf{N}^{\circ}$ & $\mathbf{R}(2)$ & $\mathbf{R}(3)$ & $\mathbf{R}(4)$ & $\mathbf{R}(5)$ & $\mathbf{R}(6)$ & BDE $\left(\mathrm{kcal} \cdot \mathrm{mol}^{-1}\right)$ \\
\hline 1 & $\mathrm{OH}$ & $\mathrm{H}$ & $\mathrm{C}\left(\mathrm{CH}_{3}\right)_{3}$ & $\mathrm{H}$ & $\mathrm{OH}$ & 66.6 (nd) \\
\hline 2 & $\mathrm{OH}$ & $\mathrm{H}$ & $\mathrm{H}$ & $\mathrm{H}$ & $\mathrm{OH}$ & $68.0(77.7[24])$ \\
\hline 3 & $\mathrm{H}$ & $\mathrm{H}$ & $\mathrm{OH}$ & $\mathrm{H}$ & $\mathrm{OH}$ & 69.1 (70.4 [25]) \\
\hline 4 & $\mathrm{OH}$ & $\mathrm{H}$ & $\mathrm{C}(\mathrm{O}) \mathrm{OC}_{3} \mathrm{H}_{7}$ & $\mathrm{H}$ & $\mathrm{OH}$ & $69.6(77.1[23])$ \\
\hline 5 & $\mathrm{C}\left(\mathrm{CH}_{3}\right)_{3}$ & $\mathrm{H}$ & $\mathrm{OCH}_{3}$ & $\mathrm{H}$ & $\mathrm{H}$ & $72.3(80.7[23])$ \\
\hline 6 & $\mathrm{H}$ & $\mathrm{H}$ & $\mathrm{C}\left(\mathrm{CH}_{3}\right)_{3}$ & $\mathrm{H}$ & $\mathrm{OH}$ & $72.3(81.1[26])$ \\
\hline 7 & $\mathrm{C}\left(\mathrm{CH}_{3}\right)_{3}$ & $\mathrm{H}$ & $\mathrm{CH}_{3}$ & $\mathrm{H}$ & $\mathrm{C}\left(\mathrm{CH}_{3}\right)_{3}$ & $72.4(79.9[27])$ \\
\hline 8 & $\mathrm{H}$ & $\mathrm{H}$ & $\mathrm{OH}$ & $\mathrm{H}$ & $\mathrm{C}\left(\mathrm{CH}_{3}\right)_{3}$ & $74.3(76.9[28])$ \\
\hline 9 & $\mathrm{H}$ & $\mathrm{H}$ & $\mathrm{CH}_{3}$ & $\mathrm{H}$ & $\mathrm{C}\left(\mathrm{CH}_{3}\right)_{3}$ & $77.4(78.1[29])$ \\
\hline 10 & $\mathrm{H}$ & $\mathrm{OH}$ & $\mathrm{H}$ & $\mathrm{OH}$ & $\mathrm{H}$ & $83.0(87.7[24])$ \\
\hline
\end{tabular}


Table 2. Cont.

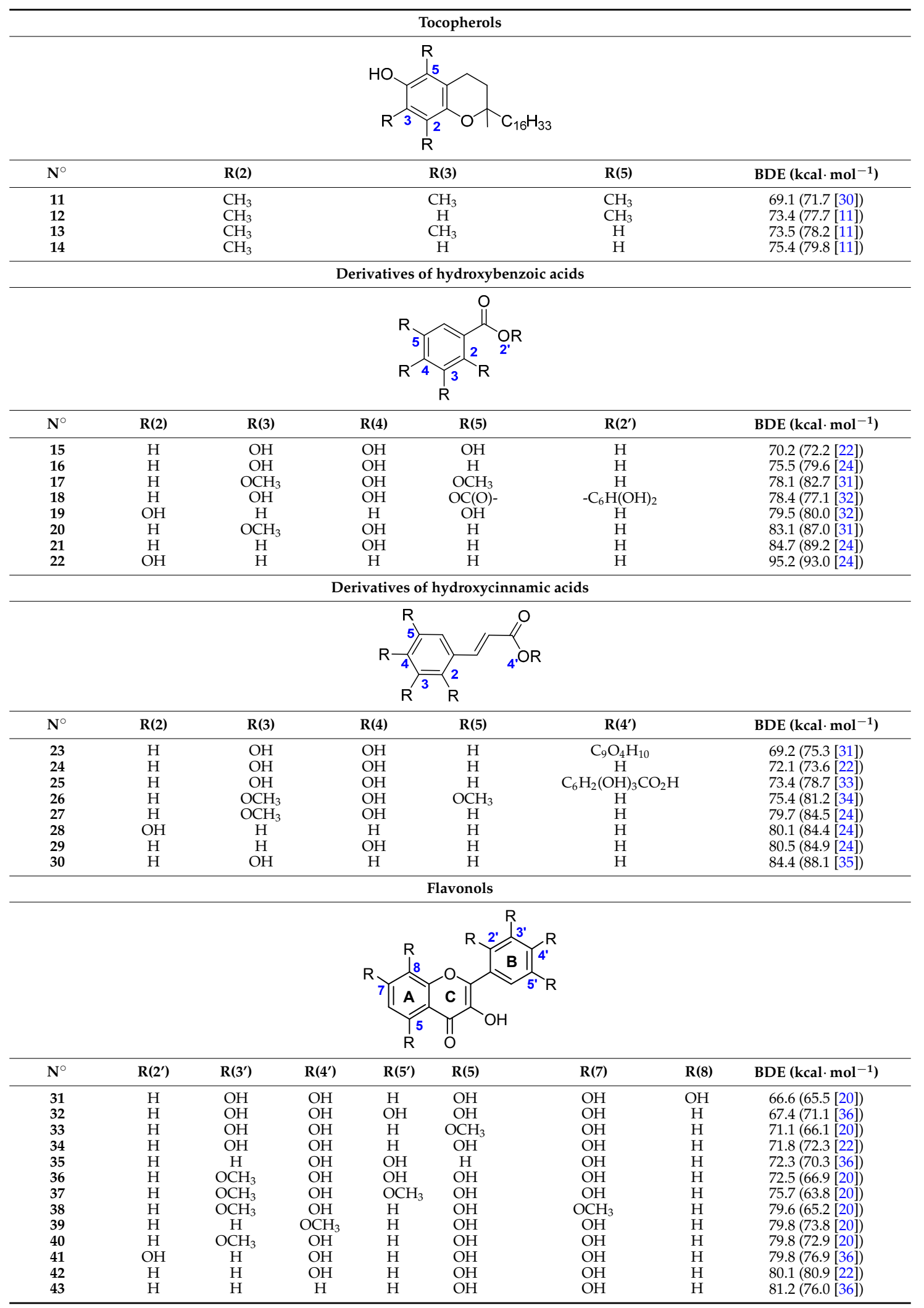


Table 2. Cont.

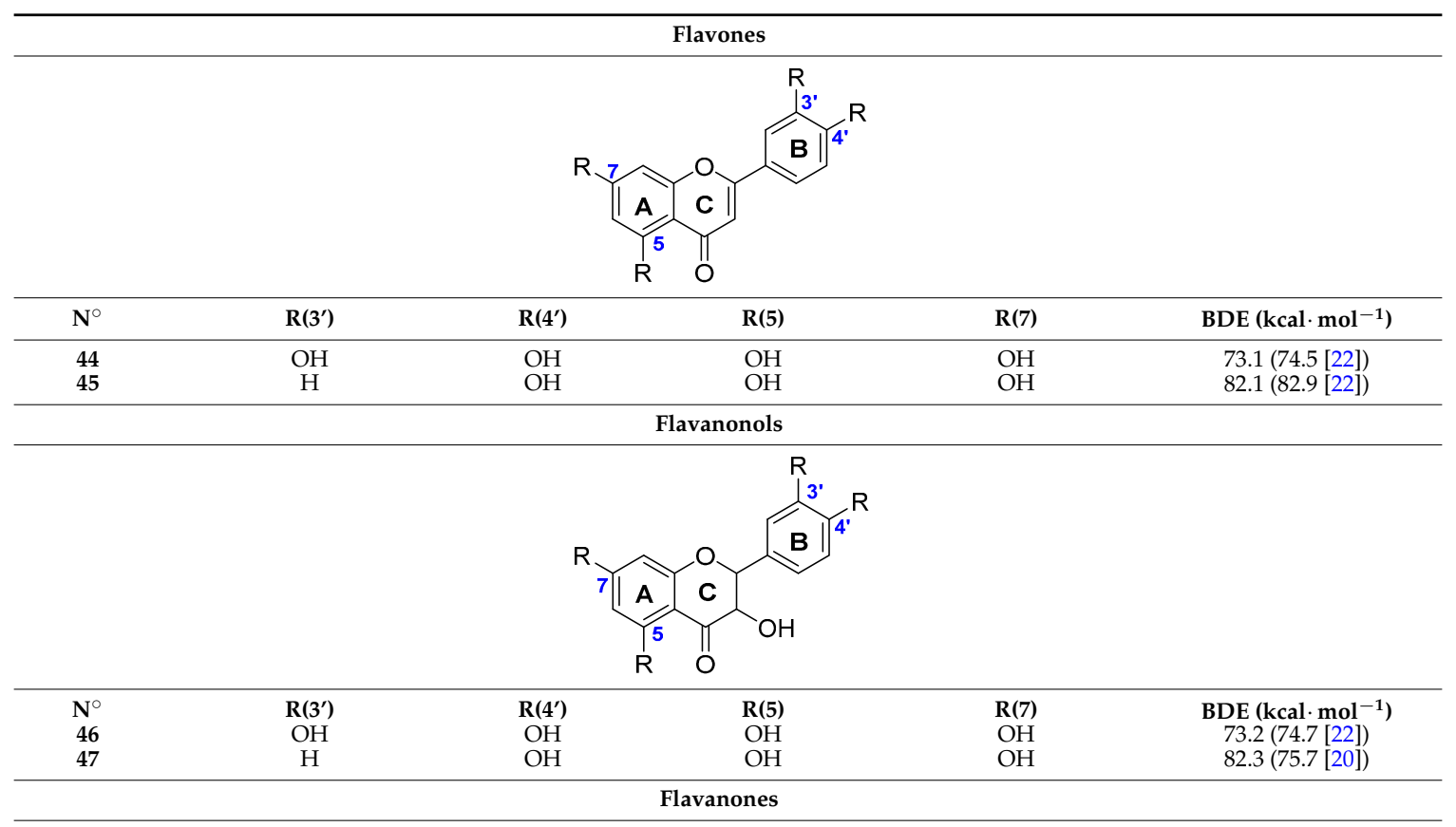

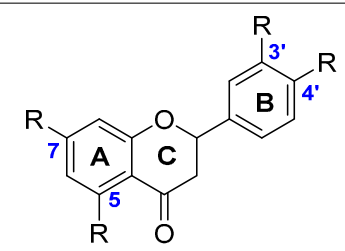

\begin{tabular}{cccccc}
\hline $\mathbf{N}^{\circ}$ & $\mathbf{R}\left(\mathbf{3}^{\prime}\right)$ & $\mathbf{R}\left(\mathbf{4}^{\prime}\right)$ & $\mathbf{R}(\mathbf{5 )}$ & $\mathbf{R}(\mathbf{7})$ & $\mathbf{B D E}_{\mathbf{( k c a l} \cdot \mathbf{~ m o l}} \mathbf{- 1}^{\mathbf{1}} \mathbf{)}$ \\
\hline $\mathbf{4 8}$ & $\mathrm{OH}$ & $\mathrm{OH}$ & $\mathrm{OH}$ & $\mathrm{OH}$ & $73.6(73.6[36])$ \\
$\mathbf{4 9}$ & $\mathrm{OCH}_{3}$ & $\mathrm{OH}$ & $\mathrm{OH}$ & $\mathrm{OH}$ & $80.8(75.1[20])$ \\
$\mathbf{5 0}$ & $\mathrm{OH}$ & $\mathrm{OCH}_{3}$ & $\mathrm{OH}$ & $\mathrm{OH}$ & $82.2(77.4[36])$ \\
$\mathbf{5 1}$ & $\mathrm{H}$ & $\mathrm{OH}$ & $\mathrm{OH}$ & & $82.4(81.4[36])$ \\
\hline
\end{tabular}

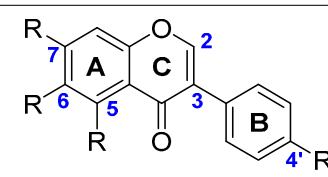

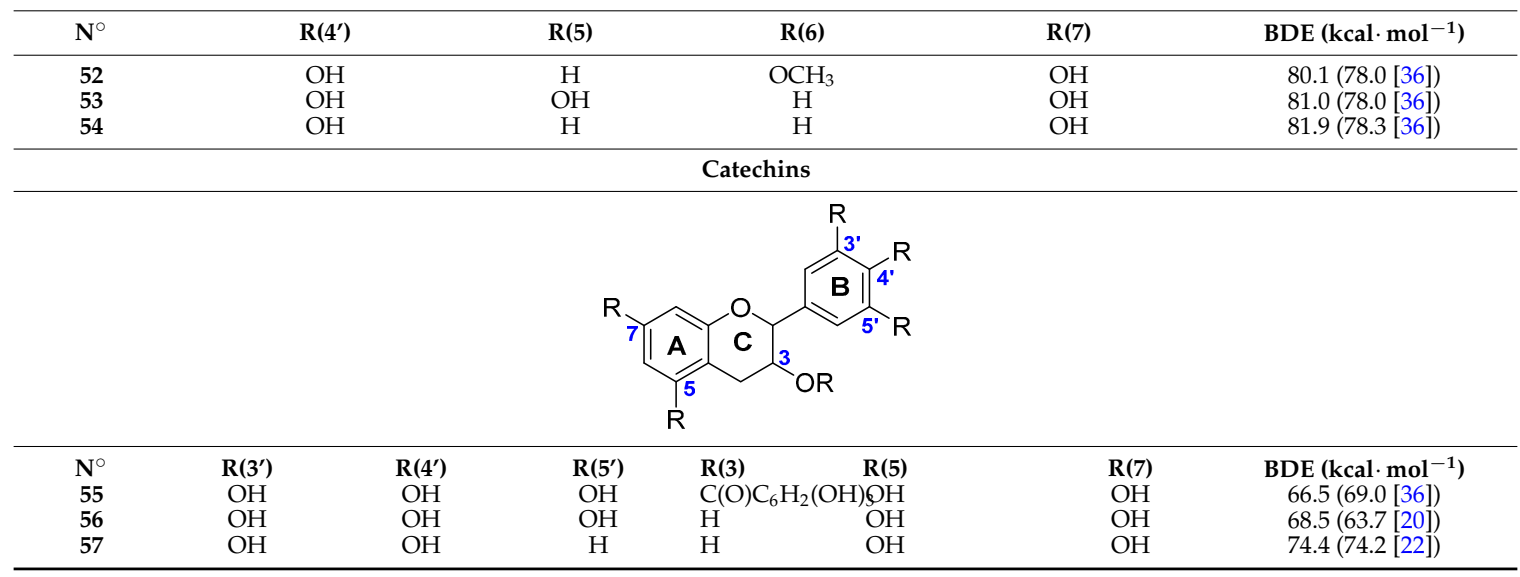


Table 2. Cont.

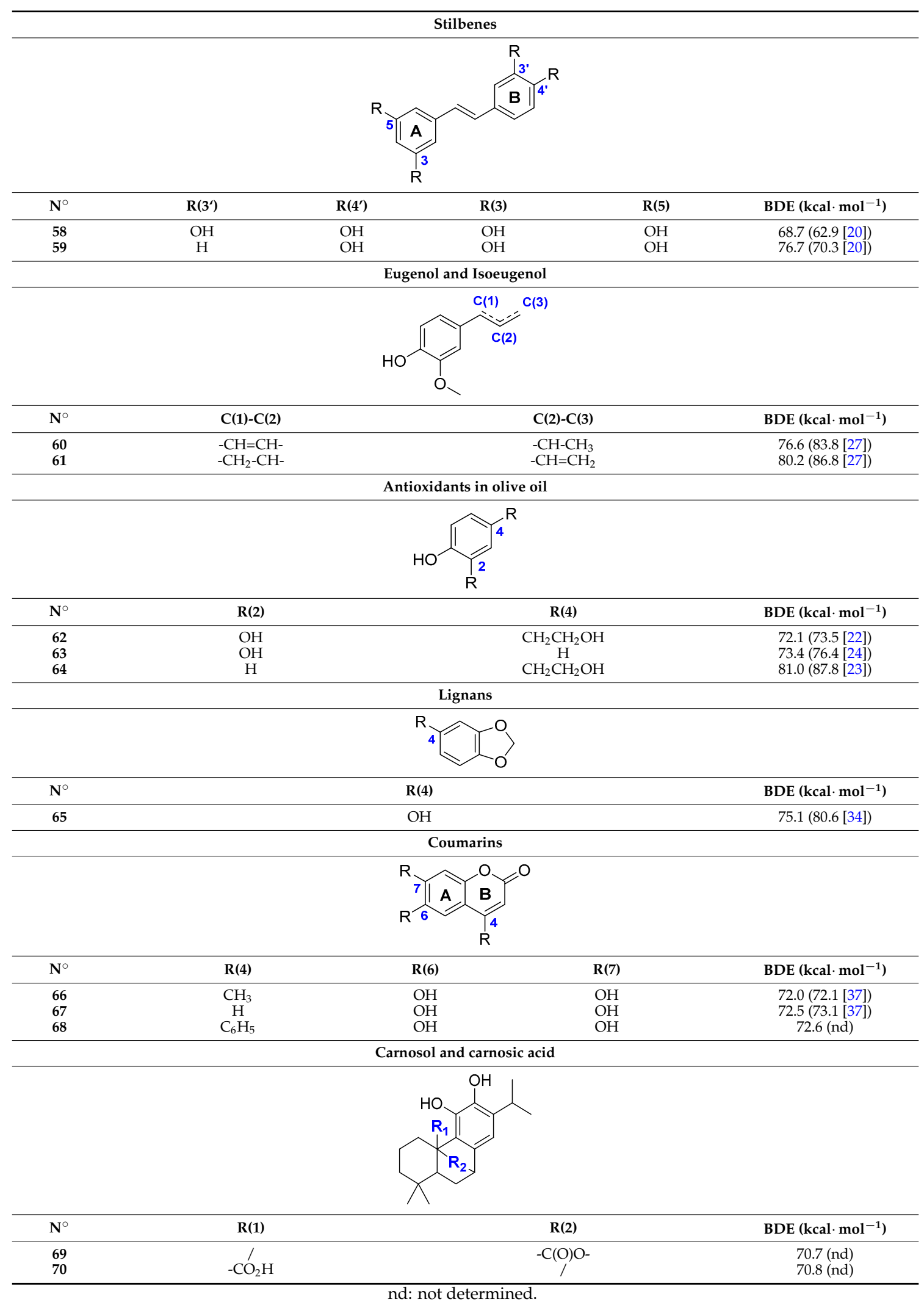

Because of toxicity, some efficient antioxidants still used for polymers are no longer tolerated in food products. In recent years, the toxicity of BHT 7 and BHA 5 have extensively been studied and they are now very controversial [38]. Consequently, their ban in the near future is expected. 
One of the current alternatives is the natural (poly)phenols. BDEs of synthetic phenols are in the following order: 5-tert-butylpyrigallol $\mathbf{1}<$ pyrogallol $\mathbf{2}<$ hydroxyquinol $\mathbf{3}<$ propyl gallate $\mathbf{4}<$ BHA $\mathbf{5}<$ 4-tert-butylcatechol $6<$ BHT $7<$ TBHQ $8<o$-tert-butyl-p-cresol $9<$ phloroglucinol 10.

Tocopherols are monophenolic compounds derived from chromanol which are very soluble in oils making $\alpha$-tocopherol $\mathbf{1 1}$ the most important antioxidant in edible fats and oils [39]. These phenols are frequently found in vegetable oils especially soybean, sunflower and palm oils. The four derivatives of tocopherol are distinguishable by the number and the position of the methyl substituents, which impact the BDEs. $\alpha$-Tocopherol 11 has the lowest BDE compared to the $\beta-, \gamma$ - and $\delta$-tocopherols.

Phenolic acids are another important class of antioxidants ubiquitous in food plants (i.e., fruit, vegetable, and coffee) [40]. There are simple phenolic acids based on hydroxybenzoic and hydroxycinnamic acids. BDEs of hydroxybenzoic acids are in the following order: Gallic acid $\mathbf{1 5}<$ protocatechuic acid $\mathbf{1 6}<$ syringic acid $\mathbf{1 7}<$ ellagic acid $\mathbf{1 8}<$ gentisic acid $\mathbf{1 9}<$ vanillic acid $20<4$-hydroxybenzoic acid (PHBA) $21<$ salicylic acid 22. Ellagic acid 18 is a particular combination of two molecules of Gallic acid and has a BDE of $78.4 \mathrm{kcal} \cdot \mathrm{mol}^{-1}$. Furthermore, the hydroxycinnamic acid with the lowest BDE is rosmarinic acid 23. It is then followed by caffeic acid $\mathbf{2 4}$, chlorogenic acid $\mathbf{2 5}$, and sinapic acid $\mathbf{2 6}$. The others derivatives of hydroxycinnamic acids have highest BDEs (BDE $>80 \mathrm{kcal} \cdot \mathrm{mol}^{-1}$ ).

The class of flavonoids gathers more than 4000 different polyphenols found in leaves, stems, roots, fruits or seeds [41]. Their general chemical structure contains three rings A, B and C (Figure 1).

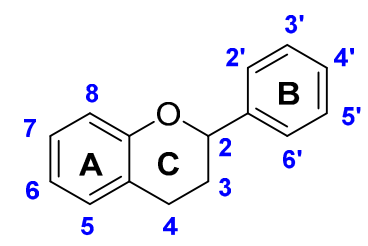

Figure 1. General chemical structure of flavonoids.

The presence of carbonyls, double bonds and hydroxyl groups on the pyranyl ring $C$ divides the flavonoids into different subclasses called flavonols, flavones, flavanonol, flavonones, isoflavone and flavanols. Substitution of A and B rings distinguishes the different phenolic antioxidants of each subclasses. The antioxidant activity of flavonoids depends on various factors [41]: (i) the metal-chelating potential that is strongly dependent on the arrangement of hydroxyls and carbonyl group around the molecule [42]; (ii) the presence of electron-donating substituents; and (iii) their ability to delocalize the unpaired electron leading to the formation of stable phenoxyl radical. Moreover, it has been shown that the phenolic ring $B$ is the most active cycle [43].

Flavonols (i.e., gossypetin 31, myricetin 32, quercetin 34 and morin 41) have the 3-hydroxyflavone backbone which includes double bond and hydroxyl group on the pyranyl ring $\mathrm{C}$. The flavonols with the lowest BDE are gossypetin $31\left(66.6 \mathrm{kcal} \cdot \mathrm{mol}^{-1}\right)$, myricetin $32\left(67.4 \mathrm{kcal} \cdot \mathrm{mol}^{-1}\right)$ and quercetin 34 $\left(71.8 \mathrm{kcal} \cdot \mathrm{mol}^{-1}\right)$. BDEs of flavonols depend on the number of hydroxyl groups and their location on the structure of flavonols, which is discussed later.

Flavones such as luteolin 44 and apigenin 45 are mainly found in cereals and herbs. They have the same chemical structure as flavonols without the hydroxyl group on the pyranyl ring C.

Flavanonols (i.e., taxifolin 46 and aromadedrin 47) and flavanones (i.e., eriodictyol 48, homoeriodictyol 49, hesperetin 50 and naringenin 51) are other classes of flavonoids. They have the same chemical structure as flavonols but without the double bond on the pyranyl ring $C$ and taxifolin 46 has a lower BDE than aromadedrin 47 . Flavonones do not have double bond and hydroxyl group on the pyranyl site $C$. The flavanone with the lowest BDE is eriodictyol $48\left(73.6 \mathrm{kcal} \cdot \mathrm{mol}^{-1}\right)$.

Isoflavones (i.e., glycetin 52, genistein 53 and daidzein 54) are also studied. They are similar with flavones except that the $\mathrm{B}$ ring is bound to the $\mathrm{C}(3)$ position instead of the $\mathrm{C}(2)$. The three isoflavones studied have almost the same $\mathrm{BDE}$. The $\mathrm{OH}$ group involved is located on the carbon $\mathrm{C}\left(4^{\prime}\right)$. 
Finally, the last class of flavonoid studied is catechins, also called flavanols, which are abundant in tea (i.e., epigallocatechin gallate 55, gallocatechin 56 and catechin 57). The catechin with the lowest $\mathrm{BDE}$ is epigallocatechin gallate $55\left(66.5 \mathrm{kcal} \cdot \mathrm{mol}^{-1}\right)$.

The two investigated stilbenes (i.e., piceatannol 58 and resveratrol 59) are natural polyphenols present in many plants such as grapes. Piceatannol 58 differs from resveratrol 59 with an $\mathrm{OH}$ group at the $\mathrm{C}\left(3^{\prime}\right)$ position which decreases the BDE.

Eugenol 61 is a phenol found in clove essence oil whereas isoeugenol 60 is present in ylang-ylang essential oil. The position of the double bond influences the BDE leading to a higher value for eugenol 61.

Hydroxytyrosol 62, catechol 63 and tyrosol 64 are antioxidants found in olive oil [44]. Hydroxytyrosol 62 is the phenol with the lowest BDE followed by catechol 63 and tyrosol 64 $\left(81.0 \mathrm{kcal} \cdot \mathrm{mol}^{-1}\right)$.

Sesamol 65 is a lignan found in sesame oil. It is a potent antioxidant and antiflammatory agent in various oxidative systems [45]. Lignans are phenyl propanoids derivated from phenylalanine and include also sesamin, sesamolin, sesaminol and sesamolinol [39].

The main coumarin called aesculetin 67 is found in tonka bean. Methyl and phenyl substituents can be grafted at the $C(4)$ position but they have no impact on BDEs.

Carnosol 69 and carnosic acid $\mathbf{7 0}$ are the two major components with rosmarinic acid $\mathbf{2 3}$ (already described) of rosemary extract (Rosmarinus officinalis L.) and are authorized in food in the form of extract [46]. For both compounds, same BDE (70.8 and $\left.70.7 \mathrm{kcal} \cdot \mathrm{mol}^{-1}\right)$ was found.

\subsection{Kinetic Rates of Hydrogen Transfer, Stoichiometric Numbersand Inhibition of FAMEs Linseed Oil Oxidation}

Thirty-two phenols $(1,4-9,11,15-17,20-27,32,34,55,58-63,65,67,69$ and 70) have been selected to cover the different classes of antioxidants and confirm their antioxidant activity through the DPPH ${ }^{\bullet}$ (2,2-diphenyl-1-picrylhydrazyl) test and during the oxidation of FAMEs linseed oil (RapidOxy ${ }^{\circledR}$ ). All these experimental methods have already been described in our previous works $[27,29,47]$.

\subsubsection{Kinetic Rates of Hydrogen Transfer}

The $\mathrm{DPPH}^{\bullet}$ test [48-53] is commonly used to evaluate the antioxidant power of phenolic compounds. $\mathrm{DPPH}^{\bullet}$ is a stable radical with a maximum of absorption around $515-520 \mathrm{~nm}$ (purple). When antioxidants are mixed with this stable radical, there is a transfer of hydrogen from the antioxidant to the $\mathrm{DPPH}^{\bullet}$ radical which becomes yellow (Equation (7)) [47]. Thus, it is easy to follow the hydrogen transfer by UV-visible spectrometry. Toluene has been chosen as a solvent because it is inert towards radical reactions and cannot create hydrogen bonding. Indeed, the polarity of the solvent can drastically change the reactivity of polar antioxidants. The mechanism involved in this apolar aprotic solvent is called hydrogen atom transfer (HAT), which is the opposite of the sequential proton loss electron transfer (SPLET) mechanism that takes place in polar solvents [29].

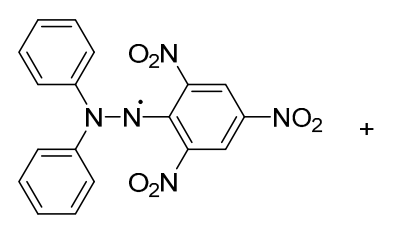

DPPH ' (Purple)

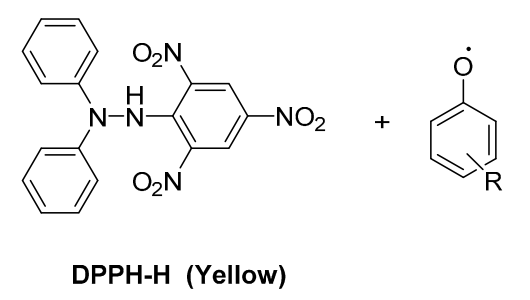

Kinetic rates $(k)$ are obtained using either pseudo-first order kinetics (FOK) or second order kinetics (SOK) depending on the reactivity of the phenol under study $[29,47]$. Reactive phenols $(\mathbf{1}, \mathbf{4}, \mathbf{5}$, $6,8,11,17,20,26,27,60,61,62,63,65,69$ and 70) were mixed with $\mathrm{DPPH}^{\bullet}$ in stoichiometric amount leading to SOK (Equation (8)) [47]. Figure 2 shows an example of SOK reaction with hydroxytyrosol 62 
in toluene. Kinetic rate constant is determined during the first 20 seconds of the reaction and only takes into account the reaction of phenolic hydrogen with $\mathrm{DPPH}^{\bullet}$.

$$
\frac{1}{\left(A-A_{\mathrm{f}}\right)}=\frac{1}{\left(A_{0}-A_{\mathrm{f}}\right)}-\frac{k}{(\varepsilon-\varepsilon)} t
$$

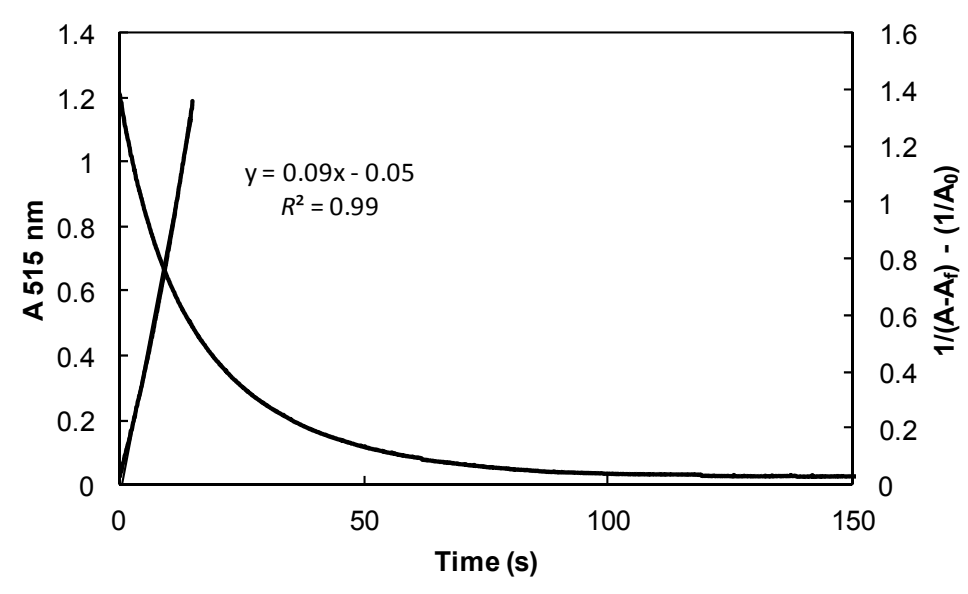

Figure 2. Evolution of the absorbance of $\mathrm{DPPH}^{\bullet}$ radical at $515 \mathrm{~nm}\left(1.25 \times 10^{-4} \mathrm{~mol} \cdot \mathrm{L}^{-1}\right)$ in the presence of hydroxytyrosol $62\left(1.25 \times 10^{-4} \mathrm{~mol} \cdot \mathrm{L}^{-1}\right)$ in toluene at $20^{\circ} \mathrm{C}$. Linearization curve according to second order kinetics (SOK) (Equation (8)).
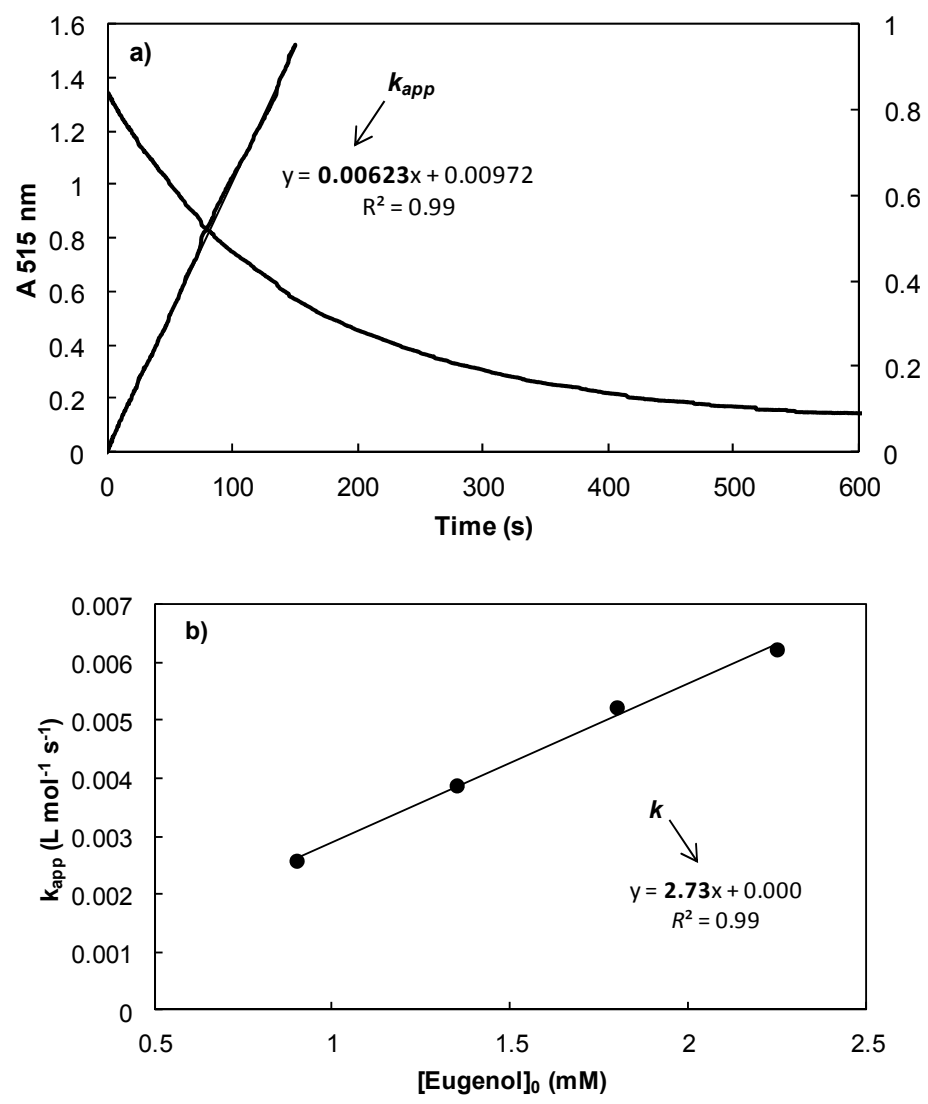

Figure 3. (a) Change in absorbance at $515 \mathrm{~nm}$ of a solution of $\mathrm{DPPH}^{\bullet}\left(1.25 \times 10^{-4} \mathrm{M}\right)$ in the presence of an excess of eugenol $61\left(2.25 \times 10^{-3} \mathrm{M}\right)$ in toluene, linearization of the logarithm of the absorbance using the final pseudo-first order kinetics (FOK) (Equation (9)) as a function time; and (b) regression constants of apparent kinetic rates as a function of initial concentrations of eugenol 61. 
On the other hand, weakly reactive phenols $(7,9,20$ and 61) are introduced in excess at different concentrations with respect to $\mathrm{DPPH}^{\bullet}$. Under these conditions, $[\mathrm{ArOH}]_{\mathrm{t}} \approx[\mathrm{ArOH}]_{0}$ and a pseudo-first order kinetics (FOK) describe the system (Equation (9)) [47]. Figure 3 shows the FOK reaction with eugenol $\mathbf{6 1}$ in toluene.

$$
\operatorname{Ln} \frac{\left(A-A_{\mathrm{f}}\right)}{\left(A_{0}-A_{\mathrm{f}}\right)}=-k[\mathrm{ArOH}]_{0} t
$$

To confirm that pseudo-first order kinetic (FOK) and second order kinetic (SOK) give the same results for the same phenolic antioxidants, vanillic acid $\mathbf{2 0}$ and eugenol $\mathbf{6 1}$ were studied using both conditions leading to similar rate constants $k$. Results are gathered in Table 3.

Table 3. Rate constants $(k)$ of hydrogen transfer from $\mathrm{ArOH}$ to $\mathrm{DPPH}{ }^{\bullet}$ in toluene at $20^{\circ} \mathrm{C}$, stoichiometric numbers of $\mathrm{H}$ atoms ( $\sigma_{\text {exp }}$ ) determined with an excess of DPPH ${ }^{\bullet}$ in toluene at $20^{\circ} \mathrm{C}$, induction periods (IP) and oxidation rates $\left(R_{\mathrm{ox}}\right)$ are determined by the RapidOxy ${ }^{\circledR}$ experiments

\begin{tabular}{|c|c|c|c|c|c|}
\hline \multirow[b]{2}{*}{$\mathbf{N}^{\circ}$} & \multicolumn{2}{|c|}{$k\left(\mathrm{M}^{-1} \cdot \mathrm{s}^{-1}\right)^{\mathrm{d}}$} & \multirow{2}{*}{$\begin{array}{c}\text { Induction Period }^{d} \\
\text { IP (min) }\end{array}$} & \multirow{2}{*}{$\begin{array}{l}\text { Oxidation Rate } \\
R_{\mathrm{ox}}\left(\mathrm{mM} \cdot \min ^{-1}\right)\end{array}$} & \multirow{2}{*}{$\begin{array}{c}\text { Stoichiometric Number } \\
\sigma_{\exp }\end{array}$} \\
\hline & SOK $^{a}$ & FOK $^{\text {b }}$ & & & \\
\hline $0^{\mathrm{e}}$ & / & / & 0 & 1.23 & / \\
\hline 1 & 9480 & & 234 & 0.06 & 2.1 \\
\hline 4 & 1240 & & 162 & 0.26 & 3.9 \\
\hline 5 & 184 & & 167 & 0.35 & 2.0 \\
\hline 6 & 776 & & 220 & 0.37 & 2.5 \\
\hline 7 & & 0.18 & 131 & 0.44 & 2.0 \\
\hline 8 & 600 & & 45 & 0.53 & 2.0 \\
\hline 9 & & 0.36 & 56 & 0.77 & 2.5 \\
\hline 11 & 2690 & & 177 & 0.17 & 2.0 \\
\hline 15 & ns & & 178 & 0.32 & $5.0^{c}$ \\
\hline 16 & ns & & 50 & 0.62 & $1.9^{c}$ \\
\hline 17 & 10.6 & & 37 & 0.76 & 1.1 \\
\hline 20 & 1.4 & 1.0 & 5 & 1.03 & $0^{c}$ \\
\hline 21 & ns & & 6 & 1.20 & $0^{c}$ \\
\hline 23 & ns & & 262 & 0.27 & $4.1^{\mathrm{c}}$ \\
\hline 24 & ns & & 148 & 0.36 & $2.0^{c}$ \\
\hline 25 & ns & & 138 & 0.48 & $1.9^{c}$ \\
\hline 26 & 165 & & 54 & 0.57 & $1.4^{\mathrm{c}}$ \\
\hline 27 & 8.4 & & 28 & 0.82 & 1.8 \\
\hline 32 & ns & & 262 & 0.11 & $3.4^{c}$ \\
\hline 34 & ns & & 135 & 0.34 & $1.9^{\mathrm{c}}$ \\
\hline 55 & ns & & 476 & 0.08 & $5.4^{\mathrm{c}}$ \\
\hline 58 & ns & & 313 & 0.29 & $2.0^{c}$ \\
\hline 59 & ns & & 67 & 0.68 & $0.9^{c}$ \\
\hline 60 & 38 & & 49 & 0.72 & 0.9 \\
\hline 61 & 3.9 & 2.7 & 27 & 0.93 & 2.1 \\
\hline 62 & 1070 & & 172 & 0.30 & 2.0 \\
\hline 63 & 400 & & 147 & 0.46 & 1.9 \\
\hline 65 & 250 & & 161 & 0.55 & 2.1 \\
\hline 67 & $\mathrm{~ns}$ & & 112 & 0.50 & 2.1 \\
\hline 69 & 1680 & & 166 & 0.35 & 1.9 \\
\hline 70 & 640 & & 230 & 0.29 & 2.0 \\
\hline
\end{tabular}

\subsubsection{Stoichiometric Number $\left(\sigma_{\exp }\right)$}

The second parameter highlighted by the $\mathrm{DPPH}^{\bullet}$ test is the number of hydrogen transferred from the phenol to the stable radical called the stoichiometric number $\left(\sigma_{\text {exp }}\right)$. It is obtained via the final absorbance reached by $\mathrm{DPPH}^{\bullet}$ in the presence of a large excess of $\mathrm{DPPH}^{\bullet}$ with respect to the antioxidant concentration [54] (Equation (10)) [29,47].

$$
\sigma_{\exp }=\frac{\left[\mathrm{DPPH}^{\bullet}\right]_{0}-\left[\mathrm{DPPH}^{\bullet}\right]_{\mathrm{f}}}{[\mathrm{ArOH}]_{0}}=\frac{A_{0}-A_{\mathrm{f}}}{\left(\varepsilon-\varepsilon^{\prime}\right)[\mathrm{ArOH}]_{0}}
$$


The mechanism of interaction between $\mathrm{DPPH}^{\bullet}$ radical and phenol takes place in two steps: (1) abstraction of the phenolic hydrogen; and (2) transfer of a second hydrogen or formation of dimers from the phenoxyl radical $\mathrm{ArO}^{\bullet}$.

All of the stoichiometric numbers $\left(\sigma_{\text {exp }}\right)$ determined for the different phenols are summarized in Table 3. Toluene was replaced by ethyl acetate when antioxidants were not soluble. Figure 4 reports the result for catechol 63.

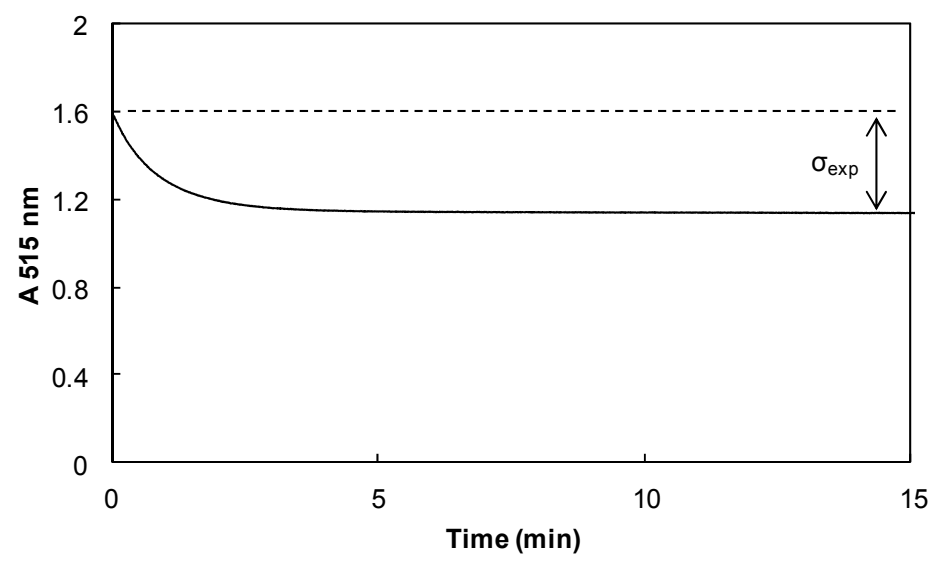

Figure 4. Evolution of the absorbance of $\mathrm{DPPH}^{\bullet}$ radical $\left(1.5 \times 10^{-4} \mathrm{~mol} \cdot \mathrm{L}^{-1}\right)$ at $515 \mathrm{~nm}$ in the presence of catechol $63\left(2.07 \times 10^{-5} \mathrm{~mol} \cdot \mathrm{L}^{-1}\right)$ in toluene at $20^{\circ} \mathrm{C}$.

\subsubsection{Inhibition of FAMEs Linseed Oil Oxidation}

FAMEs of linseed oil were synthesized by transesterification [55]. Gas chromatography-mass spectrometry (GC-MS) analysis shows that they were composed of 5.3\% methyl palmitate (C16:0), 5.3\% methyl stearate (C18:0), 33.1\% methyl oleate (C18:1), 11.2\% methyl linoleate (C18:2) and 45.1\% methyl linolenate $(\mathrm{C} 18: 3, \omega-3)$. The autoxidation of omega-3 oils in the presence of the different phenols has been kinetically investigated by measuring the oxygen consumption via RapidOxy ${ }^{\circledR}$ (Figure 5), which provides information on induction periods (IP) and oxidation rates $\left(R_{\mathrm{ox}}\right)$ [47]. The efficiency of the antioxidants depends on their solubilization into the FAMEs. Indeed, a high solubility improves its protective effects of FAMEs against oxidation.

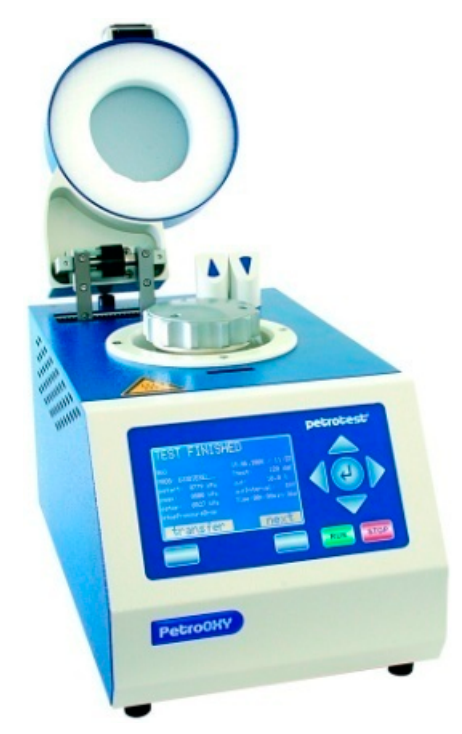

Figure 5. RapidOxy ${ }^{\circledR}$ apparatus for measurement of oxygen consumption during the autoxidation process.

As shown in Figure 6, the oxygen consumption during the oxidation process exhibits three steps: (i) the equilibration period corresponding to the increase of pressure following the increase 
of temperature after the achievement of the set pressure (450 kPa); (ii) the induction period defined by a slow decrease of the maximum pressure indicating that the antioxidant is effective; and (iii) the oxidation period characterized by a fast decrease of the oxygen consumption indicating the complete consumption of phenol which is no longer effective.

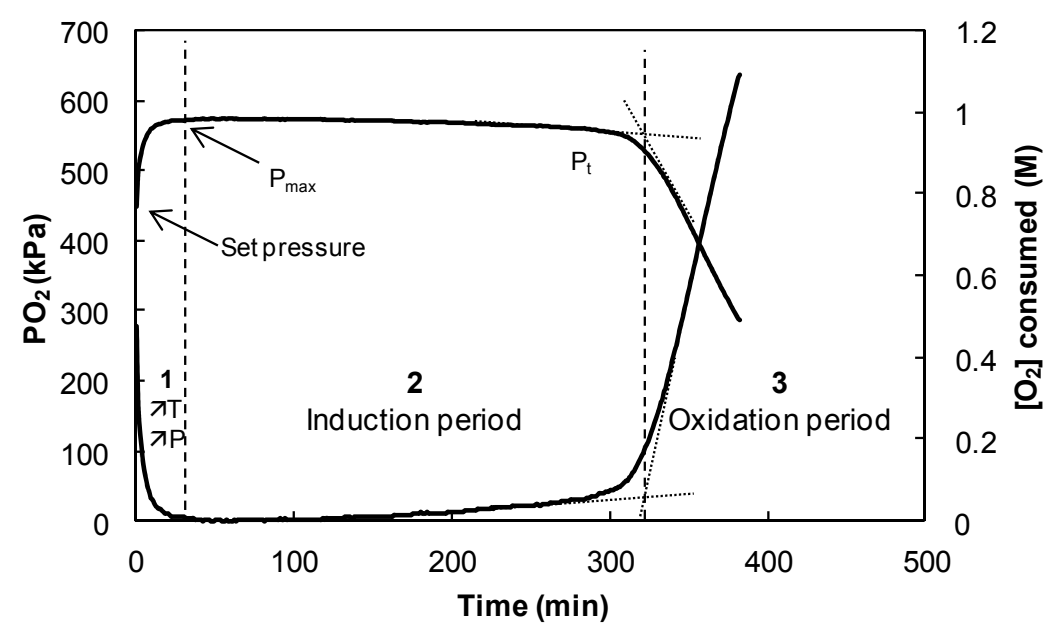

Figure 6. Evolution of the oxygen pressure (left axis) and concentration of oxygen consumed (right axis) during the oxidation of fatty acid methyl esters (FAMEs) in the presence of rosmarinic acid $\left(5 \times 10^{-4} \mathrm{~mol} \cdot \mathrm{L}^{-1}\right)$ at $90{ }^{\circ} \mathrm{C}$

The evolution of the pressure was then converted to a concentration of oxygen consumed in the liquid phase $\Delta\left[\mathrm{O}_{2}\right]_{\mathrm{t}}$ defined by Equation (11) [47], where $V_{\text {tot }}$ and $V_{\text {liq }}$ are the volumes of the cell and the FAMEs, respectively; $P_{\max }$ is the maximum pressure obtained a few minutes after heating the cell; and $P_{\mathrm{t}}$ is the pressure measured at a given time. Oxidation rate $\left(R_{\mathrm{ox}}\right)$ is defined as the rate when oxygen is consumed in the presence of antioxidants. It corresponds to the slope of the trend curve of $\left[\mathrm{O}_{2}\right]$ consumed during the induction period. The two important parameters (i.e., induction period IP and oxidation rate $R_{\mathrm{ox}}$ ) are compiled in Table 3 .

$$
\Delta\left[\mathrm{O}_{2}\right]_{t}=\frac{\left(P_{\max }-P_{\mathrm{t}}\right)}{R T} \times \frac{\left(V_{\text {tot }}-V_{\text {liq }}\right)}{V_{\text {liq }}}
$$

According to the kinetic rates constants obtained with the $\mathrm{DPPH}^{\bullet}$ test, 5-tert-butyl-pyrogallol 1 $\left(9480 \mathrm{M}^{-1} \cdot \mathrm{s}^{-1}\right)$ and propyl gallate $4\left(1240 \mathrm{M}^{-1} \cdot \mathrm{s}^{-1}\right)$ are the most reactive synthetic phenols in toluene. With regard to natural phenolic antioxidants, $\alpha$-tocopherol 11 exhibits the highest kinetic rate constants $\left(2670 \mathrm{M}^{-1} \cdot \mathrm{s}^{-1}\right)$ followed by carnosol $69\left(1680 \mathrm{M}^{-1} \cdot \mathrm{s}^{-1}\right)$, hydroxytyrosol $62\left(1070 \mathrm{M}^{-1} \cdot \mathrm{s}^{-1}\right)$ and carnosic acid $70\left(640 \mathrm{M}^{-1} \cdot \mathrm{s}^{-1}\right)$. Conversely, vanillic acid $20\left(1.4 \mathrm{M}^{-1} \cdot \mathrm{s}^{-1}\right)$, ferulic acid 27 $\left(8.4 \mathrm{M}^{-1} \cdot \mathrm{s}^{-1}\right)$ and eugenol $61\left(3.9 \mathrm{M}^{-1} \cdot \mathrm{s}^{-1}\right)$ are the least reactive phenols.

With regard to stoichiometric numbers $\left(\sigma_{\exp }\right)$, three categories of antioxidants can be identified. First, there are the antioxidants capable of trapping more than three radical molecules $(4,15,23,32$ and $\left.55, \sigma_{\exp } \geqslant 3\right)$. Then, other phenols transfer 2 or 3 hydrogens to DPPH ${ }^{\bullet}$ radical $(1,5,7,8,11,16,24$, $25,27,34,58,61,62,63,65,67,69$ and $\left.70,2 \leqslant \sigma_{\exp }<3\right)$. Finally, some compounds are not really active in the transfer of hydrogen since they trap less than two radicals per molecule of phenols $(\mathbf{1 7}, \mathbf{2 6}, 59$ and 60, $\sigma_{\text {exp }}<2$ ).

The comparison between induction periods observed for all phenolic antioxidants reveals four categories of phenols. First of all, epigallocatechin gallate 55 is by far the most reactive phenol with an induction period of about $500 \mathrm{~min}$. It is followed by piceatannol 58 (IP $=313 \mathrm{~min}$ ). These two compounds belong to category A including "extremely effective" antioxidants. Then phenols of category B (1, 6, 23, 32 and 70) exhibit induction periods from 200 to $300 \mathrm{~min}$ and are considered "highly effective" antioxidants. Furthermore, phenols of category $C(4,5,7,11,15,24,25,34,62,63$, 
65, 67 and 69) have an IP between 200 and $100 \mathrm{~min}$ and are considered as "moderately effective" antioxidants. Finally, phenols 8, 9, 16, 17, 20, 21, 26, 27, 59, 60 and 61 of category D having an induction period lower than $100 \mathrm{~min}$ are "poorly effective" antioxidants.

During the oxidation of FAMEs linseed oil, epigallocatechin gallate 55 and 5-tert-butyl-pyrogallol 1 show the lowest oxidation rate $\left(0.08\right.$ and $0.06 \mathrm{mM}^{-1} \cdot \mathrm{s}^{-1}$ respectively). Myricetin 32 also provides low oxidation rates of $0.11 \mathrm{mM}^{-1} \cdot \mathrm{s}^{-1}$, whereas, conversely, vanillic acid 20 does not reduce the oxidation rate $\left(1.03 \mathrm{mM}^{-1} \cdot \mathrm{s}^{-1}\right)$. It is noteworthy that $\alpha$-tocopherol 11 , which is the phenol of reference, does not have the lowest oxidation rate $\left(0.17 \mathrm{M}^{-1} \cdot \mathrm{s}^{-1}\right)$.

\section{Discussion}

\subsection{Bond Dissociation Enthalpies (BDE) of 70 Phenolic Antioxidants}

It is commonly admitted in the literature that BDEs of phenols are strongly influenced by the number, nature and position of the substituents linked to the phenol ring $[11,14,20,22,23,29,47,56-58]$. Nevertheless, as the results are dependent on the method of calculation used, it is difficult to compare literature values. As an example, the BDE of apigenin 45 was found to be $75.6 \mathrm{kcal} \cdot \mathrm{mol}^{-1}$ by Pérez-Gonzalez et al. [20] and $82.2 \mathrm{kcal} \cdot \mathrm{mol}^{-1}$ by Leopoldini et al. [22]. Furthermore, BDEs of 5-tert-butylpyrogallol 1, carnosol 69 and carnosic acid 70 have not been reported. Here, we use the B3LYP/6-311++G(2d,2p)//B3LYP/6-311G $(\mathrm{d}, \mathrm{p})$ method to calculate the BDE of the 70 phenols investigated. It is noteworthy that our theoretical results are globally consistent with those obtained by Leopoldini et al. $\left(R^{2}=0.98\right)$ [22], Li et al. $\left(R^{2}=0.96\right)$ [23] and Pérez-Gonzalez et al. $\left(R^{2}=0.97\right)$ [20] (see the good correlations in Figures S2-S4 in supplementary materials).

$\alpha$-Tocopherol 11 exhibits a lower BDE than $\beta-, \gamma$ - and $\delta$-tocopherols. This low BDE $\left(69.1 \mathrm{kcal} \cdot \mathrm{mol}^{-1}\right)$ results from different factors [27]: (1) the alkoxyl group in $p$-position; (2) the four alkyl substituents on the phenolic ring; (3) the molecular rigidity imposed by the pyran structure. Consequently, $\alpha$-tocopherol 11 is expected to be the most powerful tocopherol.

BDEs of hydroxybenzoic acid derivatives show that a substitution by two ortho-hydroxyl groups (Gallic acid, 15) allows a much stronger decrease of the BDE than a substitution by two ortho-methoxy groups (syringic acid, 17), which have BDEs of 70.2 and $78.1 \mathrm{kcal} \cdot \mathrm{mol}^{-1}$, respectively. Moreover, this behavior is confirmed by comparing eriodictyol $48\left(73.6 \mathrm{kcal} \cdot \mathrm{mol}^{-1}\right)$ and homoeriodictyol 49 $\left(80.8 \mathrm{kcal} \cdot \mathrm{mol}^{-1}\right)$ (Figure 7). Nevertheless, ortho-carboxyl group (salicylic acid, 22) drastically increases the BDE compared to that of phenol itself $\left(82.2 \mathrm{kcal} \cdot \mathrm{mol}^{-1}\right)$.
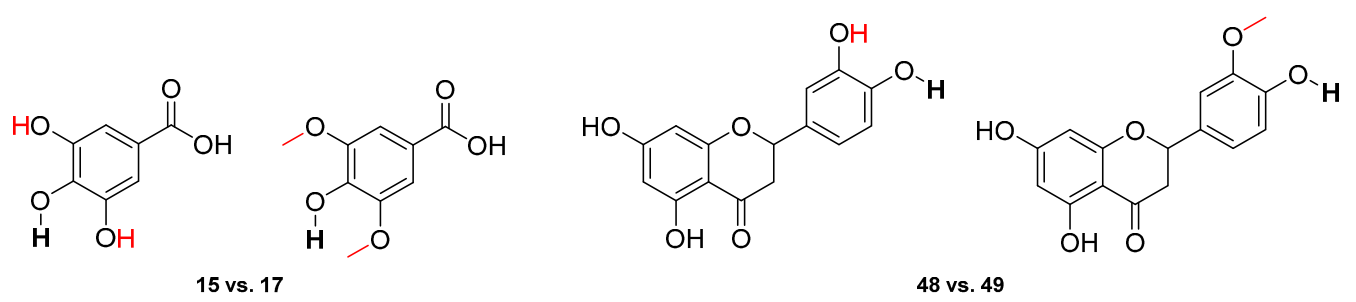

Figure 7. Comparison between gallic acid (15) and syringic acid (17) and between eriodictyol (48) with homoeriodictyol (49).

Thanks to a better delocalization of the unpaired electron for the phenolic radical, hydroxycinnamic acids have lower BDE than hydroxybenzoic acids. As a consequence, caffeic acid $24\left(72.1 \mathrm{kcal} \cdot \mathrm{mol}^{-1}\right)$ should have a better antioxidant power compared to protocatechuic acid $16\left(75.5 \mathrm{kcal} \cdot \mathrm{mol}^{-1}\right)$. Based on this argument, isoeugenol 60 has a lower BDE than eugenol 61 of $\approx 4 \mathrm{kcal} \cdot \mathrm{mol}^{-1}$ (Figure 8). 
<smiles>COc1ccc(/C=C/C(=O)O)cc1O</smiles>

24 vs. 16<smiles>C/C=C/c1ccc(O)c(OC)c1</smiles><smiles>C=CCc1ccc(O)c(OC)c1</smiles>

60 vs. 61

Figure 8. Comparison between caffeic acid (24) and protocatechuic acid (16) and between isoeugenol (60) and eugenol (61).

BDE calculations of flavonoids highlight that the flavonol with the lowest BDE is gossypetin 31 $\left(66.6 \mathrm{kcal} \cdot \mathrm{mol}^{-1}\right)$. As regards to its low BDE, it should be the most powerful flavonoid. The phenolic site involved is situated on the ring A as also demonstrated by Pérez-González et al. [20]. Except gossypetin 31, the $\mathrm{O}-\mathrm{H}$ group $\left(\mathrm{R}\left(4^{\prime}\right)\right.$ position) on the $\mathrm{B}$ ring is always the most reactive site [22]. However, flavonoids without this hydroxyl group $\left(\mathrm{R}\left(4^{\prime}\right)\right.$ position) are exceptions to this rule. As examples, kaempferide (39) and galangin (43) have their most hydroxyl reactive site on the ring $\mathrm{C}$ (C(3) position).

Flavones exhibit higher BDEs than flavonols. Indeed, luteolin $44\left(73.1 \mathrm{kcal} \cdot \mathrm{mol}^{-1}\right)$ and apigenin $45\left(82.1 \mathrm{kcal} \cdot \mathrm{mol}^{-1}\right)$ have higher BDE than quercetin $34\left(71.8 \mathrm{kcal} \cdot \mathrm{mol}^{-1}\right)$ and kaempferol 42 $\left(80.1 \mathrm{kcal} \cdot \mathrm{mol}^{-1}\right)$ respectively (Figure 9 ). This is due to the absence of $\mathrm{OH}$ group in the $\mathrm{C}$ ring. BDEs of $\mathrm{O}-\mathrm{H}$ group for flavones in site $\mathrm{R}\left(4^{\prime}\right)$ are about $10 \mathrm{kcal} \cdot \mathrm{mol}^{-1}$ higher than for flavonols. Therefore, with equivalent substituents, flavones should be less reactive than flavonols through the HAT mechanism.<smiles>O=c1cc(-c2ccc(O)c(O)c2)oc2cc(O)cc(O)c12</smiles>

Figure 9. Comparison between flavones (44 and 45) and flavonols (34 and 42).

BDEs of isoflavones studied are close to that of apigenin $45\left(82.1 \mathrm{kcal} \cdot \mathrm{mol}^{-1}\right)$ suggesting that the location of the ring $B$ does not alter the hydrogen transfer. Therefore, the antioxidant power of flavones and isoflavone should be similar when they have the same number of hydroxyl groups on the ring $B$.

Flavanonols have higher BDEs than flavonols by comparing taxifolin $46\left(73.2 \mathrm{kcal} \cdot \mathrm{mol}^{-1}\right)$ with quercetin $34\left(71.8 \mathrm{kcal} \cdot \mathrm{mol}^{-1}\right)$ and kaempferol $42\left(80.1 \mathrm{kcal} \cdot \mathrm{mol}^{-1}\right)$ with aromadedrin 47 $\left(82.3 \mathrm{kcal} \cdot \mathrm{mol}^{-1}\right)$ (Figure 10). BDEs of O-H group for flavanonols in site $\mathrm{R}\left(4^{\prime}\right)$ are about $2 \mathrm{kcal} \cdot \mathrm{mol}^{-1}$ higher than for flavonols.<smiles>O=C1c2c(O)cc(O)cc2OC(c2ccc(O)c(O)c2)C1O</smiles><smiles>O=c1c(O)c(-c2ccc(O)c(O)c2)oc2cc(O)cc(O)c12</smiles>

46 vs. 34<smiles>O=C1c2c(O)cc(O)cc2OC(c2ccc(O)cc2)C1O</smiles><smiles></smiles>

47 vs. 42

Figure 10. Comparison between flavanonols (46 and 47) and flavonols (34 and 42).

Flavanones have higher BDEs than flavonols by comparing eriodictyol $48\left(73.6 \mathrm{kcal} \cdot \mathrm{mol}^{-1}\right)$ and quercetin $34\left(71.8 \mathrm{kcal} \cdot \mathrm{mol}^{-1}\right)$ (Figure 11). BDEs of the $\mathrm{O}-\mathrm{H}$ group in site $\mathrm{R}\left(4^{\prime}\right)$ is also 
about $2 \mathrm{kcal} \cdot \mathrm{mol}^{-1}$ higher than for flavonols. That is a logical finding since the conjugation is broken due to the single bond. Therefore, the major effects are due to the neighboring groups.<smiles>O=C1CC(c2ccc(O)c(O)c2)Oc2cc(O)cc(O)c21</smiles>

Figure 11. Comparison between flavanones (48) and flavonols (34).

Substitution of the phenolic ring by two ortho-hydroxyl groups improves the stability of the central hydroxyl group and also that of the phenolic radical leading to a drastic decrease of BDEs compared to phenol $\left(82.2 \mathrm{kcal} \cdot \mathrm{mol}^{-1}\right)[11,47]$ (Equation (12)).

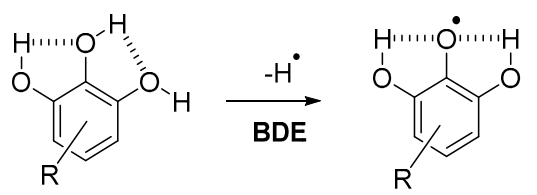

It is the case for epigallocatechin gallate $55\left(66.5 \mathrm{kcal} \cdot \mathrm{mol}^{-1}\right)$, 5-tert-butylpyrogallol 1 $\left(66.6 \mathrm{kcal} \cdot \mathrm{mol}^{-1}\right)$, myricetin $32\left(67.4 \mathrm{kcal} \cdot \mathrm{mol}^{-1}\right)$, pyrogallol $2\left(68.0 \mathrm{kcal} \cdot \mathrm{mol}^{-1}\right)$, propyl gallate $4\left(69.6 \mathrm{kcal} \cdot \mathrm{mol}^{-1}\right)$ and Gallic acid $15\left(70.2 \mathrm{kcal} \cdot \mathrm{mol}^{-1}\right)$.

Two ortho-hydroxyl groups (pyrogallol moieties) have a stronger impact on the decrease of the BDEs than only one ortho-hydroxyl function (catechol moieties). Indeed, pyrogallol structures (i.e., 5-tert-butylpyrogallol 1, pyrogallol 2, gallic acid 15, myricetin 32 and gallocatechin 55) have lower BDEs than their respective catechol compounds (i.e., 4-tert-butylcatechol 6, catechol 63, protocatechuic acid 16, quercetin 34 and catechin 57). Table 4 shows the comparison between these two types of antioxidants and highlights a systematic $\Delta \mathrm{BDE}$ of $\approx 5 \mathrm{kcal} \cdot \mathrm{mol}^{-1}$.

Table 4. BDEs comparison between pyrogallol $(\mathbf{1 5}, \mathbf{1}, \mathbf{2}, 32$ and 55) and catechol (16, 6, 63, 34 and 57) moieties.

\begin{tabular}{|c|c|c|c|c|}
\hline \multicolumn{2}{|c|}{ Pyrogallol Moieties } & \multicolumn{2}{|c|}{ Catechol Moieties } & \multirow{2}{*}{$\Delta \mathrm{BDE}\left(\mathrm{kcal} \cdot \mathrm{mol}^{-1}\right)$} \\
\hline $\mathbf{N}^{\circ}$ & BDE $\left(\mathrm{kcal} \cdot \mathrm{mol}^{-1}\right)$ & $\mathbf{N}^{\circ}$ & BDE (kcal· $\left.\mathrm{mol}^{-1}\right)$ & \\
\hline 1 & 66.6 & 6 & 72.3 & 5.7 \\
\hline 2 & 68.0 & 63 & 73.4 & 5.4 \\
\hline 15 & 70.2 & 16 & 75.5 & 5.3 \\
\hline 32 & 67.4 & 34 & 71.8 & 4.4 \\
\hline 55 & 68.5 & 57 & 74.4 & 5.9 \\
\hline
\end{tabular}

$\triangle \mathrm{BDE}=\mathrm{BDE}($ catechol $)-\mathrm{BDE}$ (pyrogallol).

Based on the BDEs of the studied phenols, a scale of predictive reactivity has been established from the lowest to the highest BDEs (Figure 12). It reveals four classes of antioxidants: (i) antioxidants with very low $\mathrm{BDE}$ from 65 to $70 \mathrm{kcal} \cdot \mathrm{mol}^{-1}$; (ii) antioxidants with low $\mathrm{BDE}$ from 70 to $75 \mathrm{kcal} \cdot \mathrm{mol}^{-1}$; (iii) antioxidants with medium BDE from 75 to $80 \mathrm{kcal} \cdot \mathrm{mol}^{-1}$; and (iv) antioxidants with high BDE from 80 to $95 \mathrm{kcal} \cdot \mathrm{mol}^{-1}$.

The antioxidants with the lowest BDEs are expected to have the best antioxidant power. 


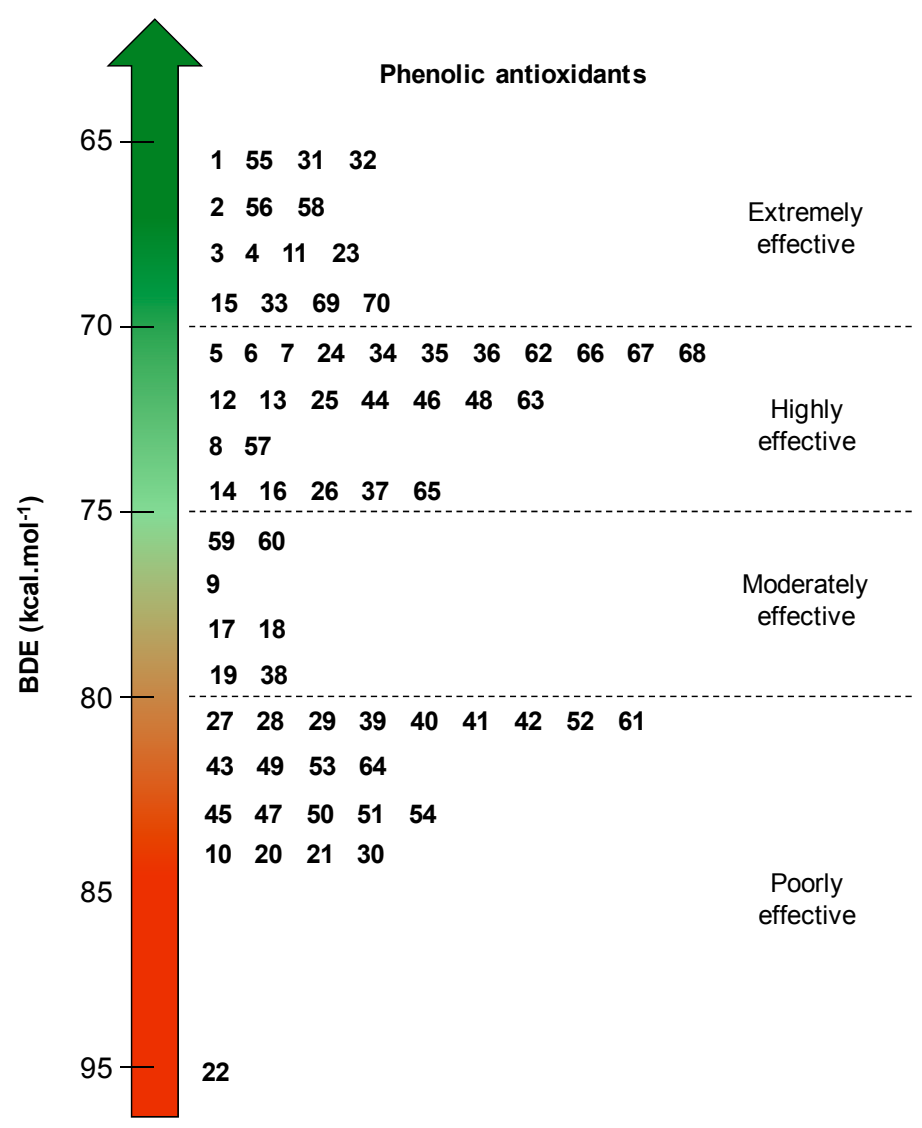

Figure 12. Scale of expected effectiveness of all the phenolic antioxidants studied (1-70) according to their BDE calculated with B3LYP/6-311++G(2d,2p)//B3LYP/6-311G(d,p) DFT method in vacuum.

Very low BDEs $\left(<70 \mathrm{kcal} \cdot \mathrm{mol}^{-1}\right)$ have been obtained for 5-tert-butylpyrogallol 1, myricetin 32, propyl gallate 4 and Gallic acid 15, which are pyrogallol derivatives. This class contains also $\alpha$-tocopherol 11 with a BDE of $69.1 \mathrm{kcal} \cdot \mathrm{mol}^{-1}$. Rosmarinic acid 23, carnosol 69 and carnosic acid 70 also exhibit a very low BDE. Indeed, they bear a catechol-type ring moiety, conjugated double bonds and alkyl substituents on the phenol rings which strongly contribute to lower the BDE.

Then, catechol 63 itself and catechol-based derivatives with flavonol structure (i.e., quercetin 34), alkyl substituent (i.e., 4-tert-butyl-catechol 6, hydroxytyrosol 62) and conjugated double bonds (i.e., caffeic acid 24 and chlorogenic acid 25) have low BDEs. Moreover, monophenols with $\mathrm{OCH}_{3}$ groups (BHA 5), ortho-and para-alkyl substituents (BHT 7) and substituted hydroquinone (TBHQ 8) belong to this second class of antioxidants. Finally, there is also catechol-based derivative with electron-withdrawing group EWG (i.e., protocatechuic acid 16) and monophenol with dioxolane moiety (i.e., sesamol 65).

The category of antioxidants with medium BDE includes monophenols with $\mathrm{OCH}_{3}$ groups (i.e., syringic acid 17, isoeugenol 60), conjugated double bond (resveratrol 59) and alkyl substituents (i.e., $o$-tert-butyl- $p$-cresol 9).

Finally, vanillic acid 20, PHBA 21, ferulic acid 27, eugenol 61 and tyrosol 64 have high BDEs and are expected to be poorly reactive considering the HAT mechanism. Moreover, the simplest structure of hydroxycinnamic acid derivatives (o-, $p$ - and $m$-coumaric acids 28, 29 and 30) and phloroglucinol 10 (phenol with two $\mathrm{OH}$ groups in meta position) have the highest BDEs. Vanillic acid 20, PHBA 21 and salicylic acid 22 have a higher BDE than phenol itself $\left(\mathrm{kcal} \cdot \mathrm{mol}^{-1}\right)$ due to the effect of electron-withdrawing group (EWG).

We can conclude that a powerful antioxidant must have pyrogallol (i.e., Gallic acid 15, myricetin 32, epigallocatechin gallate 55 and gallocatechin 56) or catechol moieties (i.e., rosmarinic acid 23, carnosol 69 and carnosic acid 70) conjugated with para-electron-donating substituents. They are the best natural alternatives to $\alpha$-tocopherol $\mathbf{1 1}$ and synthetic phenolic antioxidants. 


\subsection{Kinetic Rates of Hydrogen Transfer, Stoichiometric Numbers and Inhibition of FAMEs Linseed} Oil Oxidation

The determination of the kinetic rates of hydrogen transfer for phenolic antioxidants is a way to experimentally confirm the antioxidant properties suggested by BDE calculations. The logarithm of the rate constants for the reaction of hydrogen transfer from phenol to the $\mathrm{DPPH}^{\bullet}$ radical is very well correlated with the calculated BDE of phenols $\left(R^{2}=0.96\right)$ confirming that the radical HAT mechanism occurs in toluene [29,47] (Figure 13).

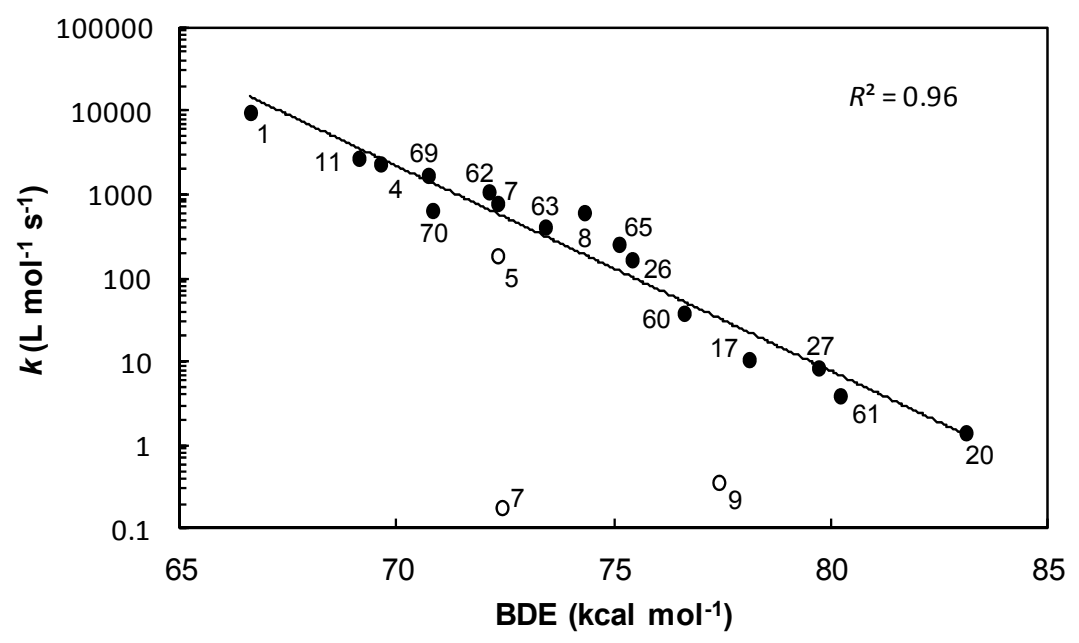

Figure 13. Logarithm of the rate constants $(\log \mathrm{k})$ for the reaction of phenolic antioxidants with DPPH (o hindered phenols and $\bullet$ other phenols) in toluene as a function of their BDEs calculated with the B3LYP / 6-311++G(2d,2p)//B3LYP/6-311G(d,p) density functional theory (DFT) method.

Nevertheless, due to the steric hindrance of the phenolic hydrogen, kinetic rates are sharply slowed down for BHA 5, BHT 7 and $o$-tert-butyl-p-cresol 9. Therefore, kinetic rates $k$ are very low and do not follow the trend curve [27,47].

Log $k$ decrease with increasing BDE has also been demonstrated by Foti et al. in heptane [34] and Marteau et al. in $m$-xylene [27]. Foti and co-workers have also proven that kinetics obtained with $\mathrm{DPPH}^{\bullet}$ are correlated with the reaction of phenols with peroxyl radicals $\mathrm{ROO}^{\bullet}[34,59]$. Indeed, this test mimics the behavior of phenolic antioxidants during the inhibition of oils oxidation thanks to hydrogen transfer through a radical mechanism. Although the conditions and the method used to determine the kinetic rates of hydrogen transfer are different, our results obtained with the DPPH ${ }^{\bullet}$ test are consistent with the literature and with our scale of reactivity based on BDEs.

These theoretical (BDE) and kinetic (DPPH ${ }^{\bullet}$ test) tools have allowed highlighting some promising effective antioxidants. Their potential antioxidant power has finally been evaluated against the oxidation of omega-3 oils derivatives (FAMEs). Figure 14 shows that the most efficient antioxidants are those with the lowest BDEs but no clear correlation between induction periods and BDEs could be obtained. There seems to be an exponential tendency $\left(R^{2}=0.86\right)$. Thereby, other parameters such as BDE influence the antioxidant power of phenols. The number of radicals trapped by molecule of antioxidant $\left(\sigma_{\text {exp }}\right)$ has an important impact on the inhibition of oxidation and influences the induction period. These stoichiometric numbers were obtained with the $\mathrm{DPPH}^{\bullet}$ test and experiments point out that the most efficient antioxidants are those with the highest stoichiometric numbers $\left(\bullet \sigma_{\exp } \geqslant 3\right)$, whereas poorly effective phenols just trap fewer than two radicals per molecule $\left(\bullet \sigma_{\exp }<2\right)$. 


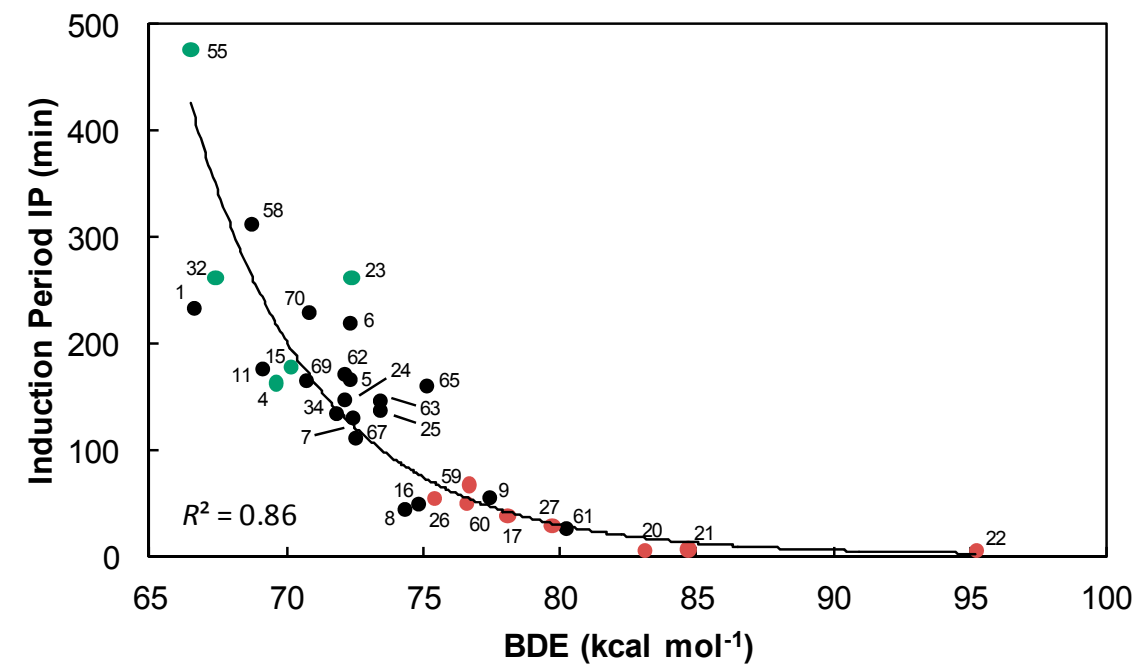

Figure 14. Induction periods (IP) as a function of the BDEs calculated with the B3LYP / 6-311++G(2d,2p)//B3LYP/6-311G(d,p) DFT method, stoichiometric numbers are indicated by: $\sigma_{\exp } \geqslant 3, \bullet 3<\sigma_{\exp } \leqslant 2$ and $\sigma_{\exp }<2$ and phenols are categorized as: extremely effective (A); highly effective (B); moderately effective (C); and poorly effective (D).

The trend displayed is clear: highly effective antioxidants are polyphenols characterized by high stoichiometric numbers. As an example, epigallocatechin gallate 55 traps more than five radicals per molecule of antioxidant and delays the oxidation process of about 500 minutes. Conversely, poorly effective antioxidants are those with low stoichiometric numbers as for syringic acid 17, isoeugenol 60 and sinapic acid 26. They transfer too few hydrogen atoms to be efficient on the delayed action of the oxidation process. Basically, moderately effective antioxidants $(4,5,7,11,15,24,25,34,62,63,65,67$ and 69) trap two radicals per molecule.

Nevertheless, there are some exceptions: Gallic acid 15 and propyl gallate 4 have higher stoichiometric numbers compared to moderately effective antioxidants. The transfer of all the hydrogen atoms from these phenols is probably too low to be competitive with the oxidation of FAMEs. Moreover, phenols with equal or higher stoichiometric numbers as moderately effective antioxidants $\left(\sigma_{\exp } \geqslant 2\right)$ could be characterized as poorly effective antioxidants as attested by their low induction periods (i.e., o-tert-butyl-p-cresol 9, ferulic acid 27 and eugenol 61). Finally, piceatannol 58, which is also considered an extremely effective antioxidant, traps only two radicals per molecule of phenol.

Accordingly, the number of radicals trapped by one molecule of phenol $\left(\sigma_{\exp }\right)$ is a crucial parameter for the protection of FAMEs against oxidation but the exceptions above-mentioned point out other essential factors as the BDE. Indeed, there is a very good correlation between oxidation rates $\left(R_{\mathrm{ox}}\right)$ and BDEs $\left(R^{2}=0.97\right.$, Figure 15$)$. We have previously described a correlation between BDEs and kinetic rates (DPPH ${ }^{\bullet}$ test) involving a transfer of hydrogen according to the radical HAT mechanism. Thereby, we assume that the mechanism involved during the inhibition of oxidation by phenolic antioxidants is also a radical mechanism.

During the oxidation of FAMEs linseed oil, the lower the rate of oxygen consumption is, the more efficient the antioxidant is. Consequently, epigallocatechin gallate 55 and 5-tert-butyl-pyrogallol 1 are the most efficient antioxidants followed by myricetin 32. Contrary to the observation made with the $\mathrm{DPPH}^{\bullet}$ test, hindered phenols (i.e., BHA 5, BHT 7 and $o$-tert-butyl-p-cresol 9) are close to the correlation straight line. Their reactions with peroxyl radicals $\mathrm{ROO}^{\bullet}$, which are less hindered than $\mathrm{DPPH}^{\bullet}$, are not inhibited and they play their antioxidant role. Antioxidants with the lowest oxidation rate $\left(R_{\mathrm{ox}}\right)$ are those with the highest stoichiometric numbers $\left(\bullet \sigma_{\exp } \geqslant 3\right)$ and conversely, poorly effective phenols are characterized by the highest $R_{\mathrm{ox}}$ and lowest stoichiometric numbers $\left(\bullet \sigma_{\mathrm{exp}}<2\right)$. 


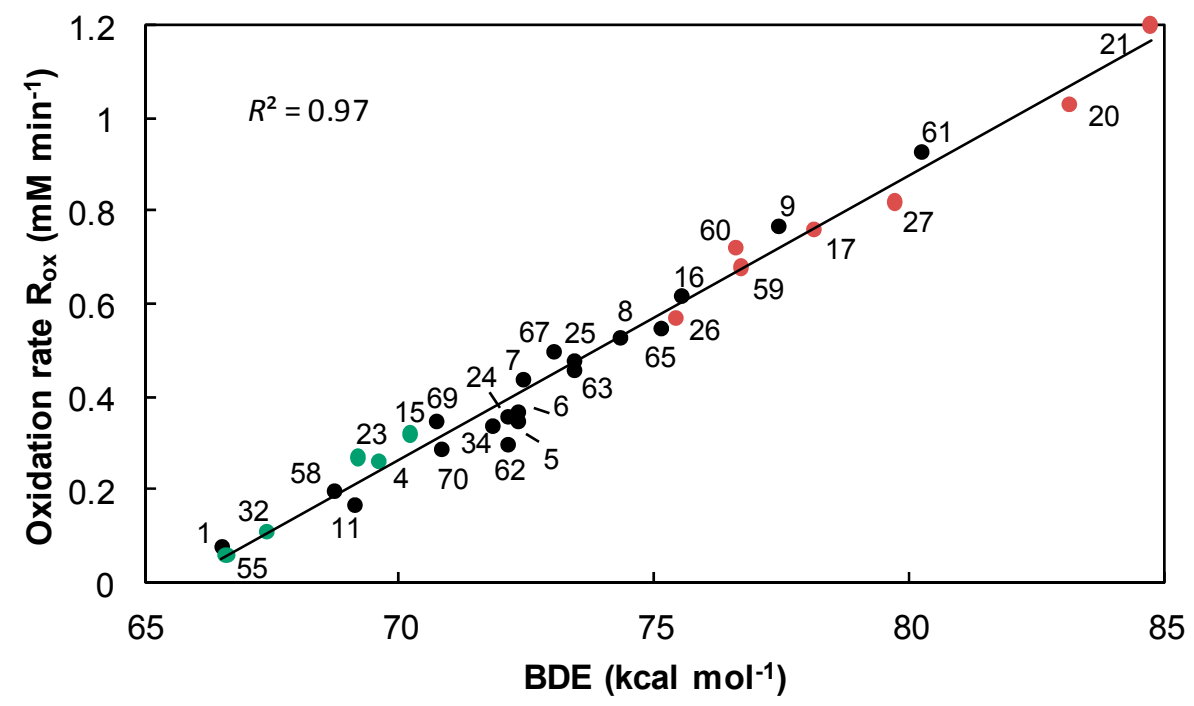

Figure 15. Oxidation rates as a function of the BDEs calculated with the B3LYP / 6-311++G(2d,2p)/ / B3LYP /6-311G(d,p) DFT method, stoichiometric numbers are indicated by: $\sigma_{\exp } \geqslant 3, \bullet 3<\sigma_{\exp } \leqslant 2$ and $\sigma_{\exp }<2$.

Consequently, the antioxidant power of phenols is determined by a combination of parameters: their BDE, the number of radicals trapped by one molecule of phenols and their ionization potential (IP) which has not been investigated here. As shown by Klein et al., the ionization potential of phenolic antioxidants has to be relatively high to be efficient in the protection of oxidized substrates [14]. Based on these characteristics, the four classes of antioxidants pointed out by the RapidOxy ${ }^{\circledR}$ experiments can be explained as follows:

First of all, epigallocatechin gallate 55 is the most effective antioxidant due to its pyrogallol and galloyl moieties, which drastically decreases the BDE $\left(66.5 \mathrm{kcal} \cdot \mathrm{mol}^{-1}\right)$ and increases the number of radicals traps by molecule $\left(\sigma_{\exp }=5.4\right)$. Moreover, even if piceatannol 58 only traps two radicals, its low BDE allows decreasing the oxidation rate of FAMEs and strongly increasing the induction period.

Then, phenols of category B $(\mathbf{1}, \mathbf{6}, \mathbf{2 3}, \mathbf{3 2}$ and $\mathbf{7 0})$ are highly effective antioxidants. Pyrogallol structures (i.e., 5-tert-butyl-pyrogallol $\mathbf{1}$ and myricetin 32) and catechol moieties (i.e., 4-tert-butyl-pyrogallol $\mathbf{6}$, rosmarinic acid 23 and carnosic acid 70) possessing ortho-, para- or conjugated electron-donating groups (EDG) have low BDEs and stoichiometric number $\left(\sigma_{\exp }\right)$ between 2.0 and 3.0.

Furthermore, phenols of category $C(4,5,7,11,15,24,25,34,62,63,65,67$ and 69$)$ are moderately effective antioxidants. Monophenols such as BHA 5, BHT 7, $\alpha$-tocopherol 11 and sesamol 65 are able to transfer two hydrogens $\left(\sigma_{\exp }=2\right)$. Moreover, all the catechol derivatives categorized as moderately effective antioxidants are just capable to transfer two hydrogens. Consequently, there is formation of ortho-quinone methide derivatives [47]. Gallic acid 15 and propyl gallate 4, identified as exception by their higher stoichiometric number (5 and 3.9, respectively), do not transfer their hydrogen enough quickly and the oxidation takes place at a rate of 0.32 and $0.26 \mathrm{mM} \cdot \mathrm{min}^{-1}$. Therefore, even if these antioxidants could transfer more than two hydrogens, they are not highly efficient for the protection of omega-3 oils.

Finally, phenols 8, 9, 10, 16, 17, 20, 21, 26, 27, 59, 60 and 61 belongs to category D and are considered as poorly effective antioxidants. Even if TBHQ 8 and protocatechuic acid $\mathbf{1 6}$ are catechol or hydroquinone derivatives capable to trap two radicals per molecule of phenol $\left(\sigma_{\exp }=2\right)$, they are poorly reactive. Indeed, $\mathbf{1 6}$ reacts very slowly with the $\mathrm{DPPH}^{\bullet}$ radical and $\mathbf{8}$ could be subjected to thermal decomposition, volatilization or absorption by the food leading to a decrease of its antioxidant power [60]. o-tert-butyl- $p$-cresol 9 transfers more than two radicals $\left(\sigma_{\exp }=2.5\right)$ per molecule but its high BDE $\left(77.4 \mathrm{kcal} \cdot \mathrm{mol}^{-1}\right)$ is not in favor of an easy transfer of hydrogens. The other phenols included in this last category are monophenolic compounds with low kinetic rates of hydrogen transfer, high BDEs and stoichiometric number lower than 2.0. 
In conclusion, to estimate the efficiency of a phenolic antioxidant, it is necessary to combine both theoretical calculations of the BDEs and kinetic measurements (DPPH ${ }^{\bullet}$ test) of the rate constants and stoichiometric numbers. Through a systematic study based on 70 phenols, several efficient antioxidants better than $\alpha$-tocopherol could be identified allowing a deeper understanding of the structure/activity relationships. The main rules that can be drawn are that antioxidants with low BDE, high kinetic rate of hydrogen transfer $(k)$ and high number of radicals trapped by one molecule of phenols $\left(\sigma_{\text {exp }}\right)$ are expected to be highly efficient providing that they act through the HAT mechanism. It appears that an efficient antioxidant should have pyrogallol or catechol moieties conjugated with para-electron-donating substituents. Apart from $\alpha$-tocopherol 11, epigallocatechin gallate 55, piceatannol 58, myricetin 32, rosmarinic acid 23 and carnosic acid $\mathbf{7 0}$ are relevant alternatives to synthetic antioxidants such as propyl gallate 4, BHA 5 and BHT 7 for the preservation of omega-3 oils.

\section{Materials and Methods}

\subsection{Reagents}

Catechol $63(\geqslant 99 \%)$, 4-hydroxybenzoic acid 21 (PHBA, $\geqslant 99 \%)$, rosmarinic acid $23(96 \%)$, quercetin $34(\geqslant 98 \%)$, 2-tert-butyl-4-methylphenol $9(99 \%)$, tert-butylhydroquinone 8 (TBHQ, 97\%), 4-hydroxy-3-methoxybenzoic acid 20 (vanillic acid, 97\%), sesamol 65 (98\%), propyl gallate 4 (PG, $\geqslant 98 \%)$, isoeugenol 60 (98\%), 3-tert-butyl-4-hydroxyanisol 5 (BHA, 98\%), 3,4-dihydroxybenzoic acid 16 (protocatechuic acid, 97\%), 2,6-di-tertbutyl-4-methylphenol 7 (BHT, $\geqslant 99 \%$ ), 3,4-dihydroxycinnamic acid 24 (caffeic acid, 97\%), ferulic acid 27 (99\%), $\alpha$-tocopherol $11(\geqslant 96 \%)$, were from Sigma-Aldrich (Lyon, France). 3,5-dimethoxy-4-hydroxycinnamic acid 26 (sinapic acid, 98\%), 5-tert-butylpyrogallol $1(97 \%)$, syringic acid $17(\geqslant 98 \%)$, eugenol $61(99 \%)$, 6,7-dihydroxycoumarin 67 (aesculetin, $\geqslant 98 \%$ ), were from Alfa Aesar (Karlsruhe, Germany). 3,4-dihydroxyphenyl ethanol 62 (hydroxytyrosol), myricetin $32(\geqslant 98 \%)$, chlorogenic acid $25(\geqslant 95 \%)$ and carnosic acid $70(\geqslant 95 \%)$ were from Cayman Chemical Company (Ann Arbor, MI, USA). Gallic acid $15(\geqslant 95 \%)$ was from Acros Organics (Geel, Belgium) and 4-tert-butylpyrogallol 6 ( $\geqslant 98 \%$ ) was from Merck (France). Resveratrol 59 ( $\geqslant 98 \%$ ) was from Tokyo Chemical Industry (TCI, Zwijndrecht, Belgium) and carnosol 69 was from Chromadex (Irvine, CA, USA). Solvents were of the purest grade commercially available from Sigma-Aldrich. The 2,2-diphenyl-1-picrylhydrazyl ( $\left.\mathrm{DPPH}^{\bullet}\right)$ radical was purchased from Sigma-Aldrich and kept at a temperature lower than $5{ }^{\circ} \mathrm{C}$. Aluminum oxide, basic, Brockmann I, for chromatography, 50-200 $\mu \mathrm{m}, 60 \AA$ was from Acros Organics (Geel, Belgium). Refined linseed oil was from Vandeputte Group, Mouscron, Belgium. FAME mix GLC-10 containing palmitic acid methyl ester (C16:0), stearic acid methyl ester (C18:0), oleic acid methyl ester (C18:1), linoleic acid methyl ester (C18:2) and linolenic acid methyl ester (C18:3) was from Supelco (Saint-Quentin Fallavier, France).

\subsection{Calculation of the Bond Dissociation Enthalpies BDEs $(\mathrm{O}-\mathrm{H})$}

The bond dissociation enthalpy or BDE is given by the difference between the enthalpy of the phenoxyl radical (plus that of the hydrogen atom) and that of the starting phenol as described by Equations (13) and (14).

$$
\begin{gathered}
\mathrm{ArO}-\mathrm{H}+\mathrm{X}^{\bullet} \rightarrow \mathrm{ArO}^{\bullet}+\mathrm{X}-\mathrm{H} \\
\mathrm{BDE}(\mathrm{ArO}-\mathrm{H})=\mathrm{H}_{\mathrm{f}}^{0}\left(\mathrm{ArO}^{\bullet}\right)+\mathrm{H}_{\mathrm{f}}^{0}\left(\mathrm{H}^{\bullet}\right)-\mathrm{H}_{\mathrm{f}}^{0}(\mathrm{ArO}-\mathrm{H})
\end{gathered}
$$

The geometries of all the parent molecules were firstly optimized using the PM3 method and then the DFT one by using the B3LYP/6-311G $(\mathrm{d}, \mathrm{p})$ basis set. The first method was used to speed up the convergence of the optimization by the second one. The zero-point energy (ZPE) is taken into account to correct the BDE values. Geometries from this method were used as inputs to the final energy B3LYP/6-311G++(2d,2p) calculation. For species having several conformers, all of them were investigated. The conformer with the lowest electronic energy is retained. For radicals, the optimization also used the PM3 step plus the final UB3LYP/6-311G $(\mathrm{d}, \mathrm{p})$ method. The zero-point energy (ZPE) is also taken into account to correct the BDE values. Geometries were then used as inputs to the final UB3LYP / 6-311G++ $(2 \mathrm{~d}, 2 \mathrm{p})$ calculation. Calculations were performed in toluene. The method is described as B3LYP/6-311++G(2d,2p)//B3LYP/6-311G $(\mathrm{d}, \mathrm{p})$. 


\subsection{Determination of the Rate Constants for Hydrogen Transfer from Phenols to DPPH}

Reactions of phenols with $\mathrm{DPPH}^{\bullet}$ are operating in toluene. Solutions of $\mathrm{DPPH}^{\bullet}$ were prepared in toluene at a concentration of approximately $5 \times 10^{-3} \mathrm{~mol} \cdot \mathrm{L}^{-1}$. For phenols 7, 9, 16, 21 and $\mathbf{6 1}$, solutions were prepared in toluene at a concentration varying from $6 \times 10^{-2}$ to $2 \times 10^{-1} \mathrm{~mol} \cdot \mathrm{L}^{-1}$. Typically, 200-500 $\mu \mathrm{L}$ of the phenol solutions were added to $500 \mu \mathrm{L}$ of DPPH${ }^{\bullet}$ solution in a $50 \mathrm{~mL}$ glass reactor equipped with a UV fiber (from Varian equipped with a dip-probe; Varian, les Ulis, France) containing $20 \mathrm{~mL}$ of deoxygenated solvent maintained at $20^{\circ} \mathrm{C}$. The hydrogen transfer reaction from phenol to the $\mathrm{DPPH}^{\bullet}$ radical was accompanied by a change in the UV-visible spectrum and was monitored at $515 \mathrm{~nm}$ with a Varian spectrophotometer (Cary 50,10 pts. $\mathrm{s}^{-1}$ ). The loss of DPPH ${ }^{\bullet}$ absorbance in the presence of an excess of phenol follows pseudo-first-order kinetics (FOK). The rate constants were determined for poorly reactive phenols 7, 9, 16, 21 and $\mathbf{6 1}$ for at least four different phenol concentrations by plotting $k_{\mathrm{DPPH}} \bullet$ versus [phenol]. In the case of other highly/moderately reactive phenols, the reaction with the $\mathrm{DPPH}^{\bullet}$ radical is very fast and the rate constant were determined by using stoichiometric conditions considering second order kinetics (SOK). For these phenols, solutions were prepared in toluene at a concentration of approximately $5 \times 10^{-3} \mathrm{~mol} \cdot \mathrm{L}^{-1}$. Equipment for $\mathrm{UV}$-visible analysis (Agilent, Les Ulis, France) and curve presenting the visualization of the lag time are presented in Figure S1. Values of the rate constants are given in the supplementary materials (Table S2). Under these conditions, $\varepsilon$ and $\varepsilon^{\prime}$ values are $11,788 \mathrm{~L} \cdot \mathrm{mol}^{-1} \cdot \mathrm{cm}^{-1}$ and $24 \mathrm{~L} \cdot \mathrm{mol}^{-1} \cdot \mathrm{cm}^{-1}$ for DPPH and DPPH-H respectively [29].

\subsection{Determination of the Stoichiometric Number $\left(\sigma_{\text {exp }}\right)$ for the Reaction of Phenolic Antioxidants with DPPH ${ }^{\bullet}$}

Solutions of $\mathrm{DPPH}^{\bullet}$ are prepared in toluene at a concentration of ca. $1.5 \times 10^{-4} \mathrm{M}$ by sonicating the mixture until all DPPH${ }^{\bullet}$ crystals were dissolved. The solutions are then maintained under argon at $20^{\circ} \mathrm{C}$. For phenols, solutions are also prepared in toluene at a concentration of $2.07 \times 10^{-3} \mathrm{M}$ by sonicating until all crystals are dissolved. Typically, $20 \mu \mathrm{L}$ of the phenol solutions are added to $2.0 \mathrm{~mL}$ of a DPPH${ }^{\bullet}$ solution in a UV cell stirred and maintained at $20^{\circ} \mathrm{C}$. The absorbance change is monitored at $515 \mathrm{~nm}$ by using the UV-Visible Cary 60 (Agilent, Les Ulis, France) every seconds or minutes. Final $\left(A_{\mathrm{f}}\right)$ and initial $\left(A_{0}\right)$ absorbances are used to determine the stoichiometric number $\left(\sigma_{\exp }\right)$ according to Equation (15). Final absorbances are collected when constant values are reached during at least thirty minutes. Values of the stoichiometric numbers are summarized in Table 3 and detailed in the Supplementary Information (Table S3) [30].

$$
\sigma_{\exp }=\frac{\left[\mathrm{DPPH}^{\bullet}\right]_{0}-\left[\mathrm{DPPH}^{\bullet}\right]_{\mathrm{f}}}{[\mathrm{ArOH}]_{0}}=\frac{A_{0}-A_{\mathrm{f}}}{\left(\varepsilon-\varepsilon^{\prime}\right)[\mathrm{ArOH}]_{0}}
$$

\subsection{Synthesis of Antioxidant-Free Fatty Acid Methyl Esters (FAMEs) by Transesterification of Purified Linseed Oil}

Linseed oil was beforehand purified 3 times by alumina column chromatography to reach very low concentration of antioxidants naturally present in neat oil. The transesterification reaction of triglycerides of purified linseed oil with methanol into fatty acid methyl esters (FAMEs) is given in Equation (16). One liter of methanol was introduced into a $2 \mathrm{~L}$ three-necked equipped with a condenser and a gas bubbling. Sodium (10 g, 2 equiv.) was introduced piece by piece under argon followed by purified linseed oil (200 g, 1 equiv.). The reaction was performed during $12 \mathrm{~h}$ under magnetic stirrer. FAMEs were extracted with $3 \times 300 \mathrm{~mL}$ of petroleum ether. The combined organic phases were evaporated under pressure. Isolated FAMEs were stored at $-20^{\circ} \mathrm{C}$.

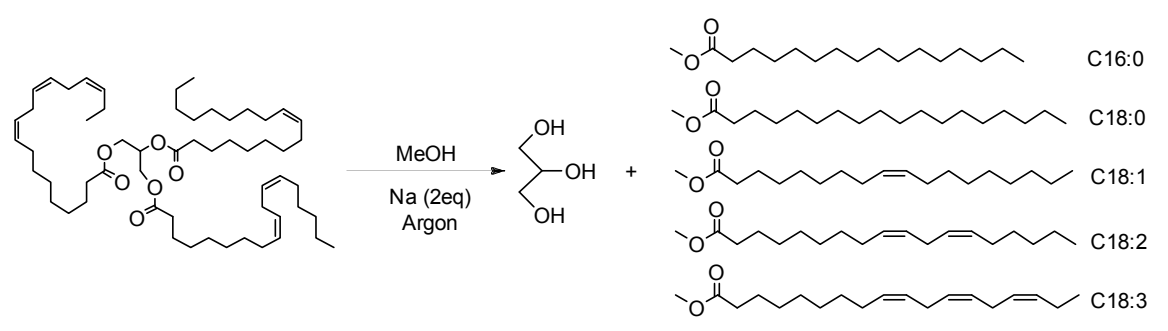




\subsection{Analysis of FAMEs Linseed Oil by GC-MS}

A Thermofisher (Courtaboeuf, France) GC Trace equipped with an AI 3000 injector connected to DSQ II simple quadrupole detector was used for the GC-MS analysis of FAMEs. Compound separation was achieved on a $30 \mathrm{~m}$, DB5MS with $0.25 \mathrm{~mm}$ i.d. and $0.25 \mu \mathrm{m}$ film thickness gas chromatographic column (J \& W Scientific, Folsom, CA, USA). Carrier gas (ultra-pure helium) flow rate is $1.0 \mathrm{~mL} / \mathrm{min}$ and the injector, the transfer line and the ions source were maintained at 250, 270 and $220^{\circ} \mathrm{C}$, respectively. The mass spectrometry (MS) detector was used in the electron ionization (EI) mode with an ionization voltage of $70 \mathrm{eV}$. The column was held at $130{ }^{\circ} \mathrm{C}$ for $0.5 \mathrm{~min}$ and then programmed at $0.3^{\circ} \mathrm{C} \cdot \mathrm{min}^{-1}$ to $180^{\circ} \mathrm{C}$ and maintained for $5 \mathrm{~min}$. Then, the column was programmed at $3{ }^{\circ} \mathrm{C} \cdot \mathrm{min}^{-1}$ to $250{ }^{\circ} \mathrm{C}$ and maintained for $10 \mathrm{~min}$. The compounds were injected in the Split mode with a ratio of 20. FAME mix GLC-10 (Sigma Aldrich, Lyon, France) was used to analyze and quantify the FAMEs composition.

\subsection{Effect of the Phenolic Antioxidants on the Autoxidation of Fames Linseed Oil}

Two-milliliter FAMEs of linseed oil were introduced into the RapidOxy cell $(25 \mathrm{~mL})$ at room temperature. One hundred microliters of phenol $(\mathbf{1}, 4,5,6,7, \mathbf{8}, \mathbf{9}, \mathbf{1 1}, \mathbf{1 5}, \mathbf{1 6}, \mathbf{1 7}, \mathbf{2 0}, \mathbf{2 1}, \mathbf{2 2}, \mathbf{2 3}, \mathbf{2 4}, \mathbf{2 5}, 26$, $27,32,34,55,58,59,60,61,62,63,65,67,69$ and 70$)$ solutions $\left(10^{-2} \mathrm{~mol} \cdot \mathrm{L}^{-1}\right)$ were then added to reach a final antioxidant concentration of $5 \times 10^{-4} \mathrm{~mol} \cdot \mathrm{L}^{-1}$. Antioxidants are solubilized in ethyl acetate and an ultrasound bath is used to homogenize solutions. Few amount of ethanol could be firstly used to pre-solubilize antioxidants not soluble in ethyl acetate. The cell was the closed and heated up to the temperature set $\left(90^{\circ} \mathrm{C}\right)$ under a pure oxygen pressure of $450 \mathrm{kPa}$. The $\mathrm{O}_{2}$ consumption was followed by monitoring the $\mathrm{O}_{2}$ pressure. The experiment was ended when the pressure reached $50 \%$ of the maximum pressure. The pressure decrease was converted into a concentration of oxygen per volumes of the FAMEs solution. Values of the induction periods and oxidation rates are summarized in Table 3 and detailed in the Supplementary Information (Table S4).

Supplementary Materials: Supplementary materials can be found at http://www.mdpi.com/1422-0067/ 17/8/1220/s1.

Acknowledgments: Chevreul Institute (FR 2638), Ministère de l'Enseignement Supérieur et de la Recherche, Région Nord-Pas de Calais, FEDER and the company Cargill are acknowledged for supporting and funding partially this work.

Author Contributions: The three authors equally contributed to this research article. This work is a part of the PhD thesis of Romain Guitard who was supervised by Véronique Nardello-Rataj and Jean-Marie Aubry.

Conflicts of Interest: The authors declare no conflict of interest.

\section{Abbreviations}

$\begin{array}{ll}\text { BHT } & \text { Butylated hydroxytoluene } \\ \text { BDE } & \text { Bond dissociation enthalpy } \\ \text { BHA } & \text { Butylated hydroxyanisole } \\ \text { DFT } & \text { Density functional theory } \\ \text { TBHQ } & \text { tert-Butylhydroquinone } \\ \text { EDG } & \text { Electron-donating group } \\ \text { PG } & \text { Propyl gallate } \\ \text { EWG } & \text { Electron-withdrawing group } \\ \text { FOK } & \text { Pseudo-first-order kinetic } \\ \text { LOO } & \text { Lipid peroxyl radical } \\ \text { SOK } & \text { Second order kinetic } \\ \text { LOOH } & \text { Lipid hydroperoxide } \\ \text { DPPH } & \text { 2,2-Diphenyl-1-picrylhydrazyl } \\ \text { HAT } & \text { Hydrogen atom transfer } \\ \text { FAMEs } & \text { Fatty acid methyl esters } \\ \text { IP } & \text { Induction period } \\ \text { LH } & \text { Unsaturated lipids } \\ R_{\mathrm{Ox}} & \text { Oxidation rate }\end{array}$




\section{References}

1. Burr, M.L. Lessons from the story of n-3 fatty acids. Am. J. Clin. Nutr. 2000, 71, 397S-398S. [PubMed]

2. Kryzhanovskii, S.A.; Vititnova, M.B. $\Omega-3$ polyunsaturated fatty acids and the cardiovascular system. Hum. Physiol. 2009, 35, 491-501. [CrossRef]

3. Kanner, J.; Rosenthal, I. An assessment of lipid oxidation in foods. Pure Appl. Chem. 1992, 64, $1959-1964$. [CrossRef]

4. Miyamoto, S.; Martinez, G.R.; Medeiros, M.H.G.; di Mascio, P. Singlet molecular oxygen generated from lipid hydroperoxides by the russell mechanism: Studies using 18(O)-labeled linoleic acid hydroperoxide and monomol light emission measurements. J. Am. Chem. Soc. 2003, 125, 6172-6179. [CrossRef] [PubMed]

5. Neff, W.E.; Frankel, E.N. Photosensitized oxidation of methyl linolenate monohydroperoxides: Hydroperoxy cyclic peroxides, dihydroperoxides and hydroperoxy bis(cyclic peroxide)s. Lipids 1984, 19, 952-957. [CrossRef]

6. Halliwell, B.; Aeschbach, R.; Löliger, J.; Aruoma, O.I. The characterization of antioxidants. Food Chem. Toxicol. 1995, 33, 601-617. [CrossRef]

7. Zhang, H.-Y.; Sun, Y.-M.; Wang, X.-L. Substituent effects on o-h bond dissociation enthalpies and ionization potentials of catechols: A dft study and its implications in the rational design of phenolic antioxidants and elucidation of structure-activity relationships for flavonoid antioxidants. Chem. Eur. J. 2003, 9, 502-508. [CrossRef] [PubMed]

8. Van Acker, S.A.B.E.; Koymans, L.M.H.; Bast, A. Molecular pharmacology of vitamin e: Structural aspects of antioxidant activity. Free Radical Biol. Med. 1993, 15, 311-328. [CrossRef]

9. Zhang, H.-Y. Theoretical methods used in elucidating activity differences of phenolic antioxidants. J. Am. Oil Chem. Soc. 1999, 76, 745-748. [CrossRef]

10. Wright, J.S.; Carpenter, D.J.; McKay, D.J.; Ingold, K.U. Theoretical calculation of substituent effects on the o-h bond strength of phenolic antioxidants related to vitamin e. J. Am. Chem. Soc. 1997, 119, 4245-4252. [CrossRef]

11. Wright, J.S.; Johnson, E.R.; DiLabio, G.A. Predicting the activity of phenolic antioxidants: Theoretical method, analysis of substituent effects, and application to major families of antioxidants. J. Am. Chem. Soc. 2001, 123, 1173-1183. [CrossRef] [PubMed]

12. Zhang, H.-Y. Selection of theoretical parameter characterizing scavenging activity of antioxidants on free radicals. J. Am. Oil Chem. Soc. 1998, 75, 1705-1709. [CrossRef]

13. Zhang, H.-Y. On the o-h bond dissociation enthalpy of catechol. New J. Chem. 2003, 27, 453-454. [CrossRef]

14. Klein, E.; Lukes, V. Study of gas-phase $\mathrm{O}-\mathrm{H}$ bond dissociation enthalpies and ionization potentials of substituted phenols-applicability of ab initio and DFT/B3LYP methods. Chem. Phys. 2006, 330, 515-525. [CrossRef]

15. Klein, E.; Lukes, V.; Cibulkova, Z.; Polovkova, J. Study of N-H, O-H, and S-H bond dissociation enthalpies and ionization potentials of substituted anilines, phenols, and thiophenols. J. Mol. Struct. Theochem 2006, 758, 149-159. [CrossRef]

16. Pratt, D.A.; DiLabio, G.A.; Brigati, G.; Pedulli, G.F.; Valgimigli, L. 5-Pyrimidinols: Novel chain-breaking antioxidants more effective than phenols. J. Am. Chem. Soc. 2001, 123, 4625-4626. [CrossRef] [PubMed]

17. Bowry, V.W.; Ingold, K.U. The unexpected role of vitamin E ( $\alpha$-tocopherol) in the peroxidation of human low-density lipoprotein. Acc. Chem. Res. 1999, 32, 27-34. [CrossRef]

18. Gotoh, N.; Noguchi, N.; Tsuchiya, J.; Morita, K.; Sakai, H.; Shimasaki, H.; Niki, E. Inhibition of oxidation of low density lipoprotein by vitamin e and related compounds. Free Radic. Res. 1996, 24, 123-134. [PubMed]

19. Noguchi, N.; Okimoto, Y.; Tsuchiya, J.; Cynshi, O.; Kodama, T.; Niki, E. Inhibition of oxidation of low-density lipoprotein by a novel antioxidant, BO-653, prepared by theoretical design. Arch. Biochem. Biophys. 1997, 347, 141-147. [CrossRef] [PubMed]

20. Perez-Gonzalez, A.; Rebollar-Zepeda, A.M.; Leon-Carmona, J.R.; Galano, A. Reactivity indexes and O-H bond dissociation energies of a large series of polyphenols: Implications for their free radical scavenging activity. J. Mex. Chem. Soc. 2012, 56, 241-249.

21. Bakalbassis, E.G.; Lithoxoidou, A.T.; Vafiadis, A.P. Theoretical calculation of accurate absolute and relative gas- and liquid-phase $\mathrm{O}-\mathrm{H}$ bond dissociation enthalpies of 2-mono- and 2,6-disubstituted phenols, using dft/b3lyp. J. Phys. Chem. A 2003, 107, 8594-8606. [CrossRef] 
22. Leopoldini, M.; Russo, N.; Toscano, M. The molecular basis of working mechanism of natural polyphenolic antioxidants. Food Chem. 2010, 125, 288-306. [CrossRef]

23. Li, M.-J.; Liu, L.; Fu, Y.; Guo, Q.-X. Accurate bond dissociation enthalpies of popular antioxidants predicted by the oniom-g3b3 method. J. Mol. Struct. Theochem 2007, 815, 1-9. [CrossRef]

24. Hoelz, L.V.B.; Horta, B.A.C.; Araujo, J.Q.; Albuquerque, M.G.; Bicca de Alencastro, R.; da Silva, J.F.M. Quantitative structure-activity relationships of antioxidant phenolic compounds. J. Chem. Pharm. Res. 2010, 2, 291-306.

25. Thavasi, V.; Leong, L.P.; Bettens, R.P.A. Investigation of the influence of hydroxy groups on the radical scavenging ability of polyphenols. J. Phys. Chem. A 2006, 110, 4918-4923. [CrossRef] [PubMed]

26. Amorati, R.; Ferroni, F.; Lucarini, M.; Pedulli, G.F.; Valgimigli, L. A quantitative approach to the recycling of $\alpha$-tocopherol by coantioxidants. J. Org. Chem. 2002, 67, 9295-9303. [CrossRef] [PubMed]

27. Marteau, C.; Nardello-Rataj, V.; Favier, D.; Aubry, J.M. Dual role of phenols as fragrances and antioxidants: Mechanism, kinetics and drastic solvent effect. Flavour Frag. J. 2013, 28, 30-38. [CrossRef]

28. Nehru, K.; Jang, Y.; Oh, S.; Dallemer, F.; Nam, W.; Kim, J. Oxidation of hydroquinones by a nonheme iron(iv)-oxo species. Inorg. Chim. Acta 2008, 361, 2557-2561. [CrossRef]

29. Marteau, C.; Guitard, R.; Penverne, C.; Favier, D.; Nardello-Rataj, V.; Aubry, J.M. Boosting effect of ortho-propenyl substituent on the antioxidant activity of natural phenols. Food Chem. 2016, 196, 418-427. [CrossRef] [PubMed]

30. Leopoldini, M.; Marino, T.; Russo, N.; Toscano, M. Antioxidant properties of phenolic compounds: H-atom versus electron transfer mechanism. J. Phys. Chem. A 2004, 108, 4916-4922. [CrossRef]

31. Nenadis, N.; Tsimidou, M.Z. Contribution of dft computed molecular descriptors in the study of radical scavenging activity trend of natural hydroxybenzaldehydes and corresponding acids. Food Res. Int. 2012, 48, 538-543. [CrossRef]

32. Chen, Y.; Xiao, H.; Zheng, J.; Liang, G. Structure-thermodynamics-antioxidant activity relationships of selected natural phenolic acids and derivatives: An experimental and theoretical evaluation. PLoS ONE 2015, 10, e0121276. [CrossRef] [PubMed]

33. Amorati, R.; Pedulli, G.F.; Cabrini, L.; Zambonin, L.; Landi, L. Solvent and ph effects on the antioxidant activity of caffeic and other phenolic acids. J. Agric. Food Chem. 2006, 54, 2932-2937. [CrossRef] [PubMed]

34. Foti, M.C.; Daquino, C.; Mackie, I.D.; DiLabio, G.A.; Ingold, K.U. Reaction of phenols with the 2,2-diphenyl-1-picrylhydrazyl radical: Kinetics and dft calculations applied to determine aro-h bond dissociation enthalpies and reaction mechanism. J. Org. Chem. 2008, 73, 9270-9282. [CrossRef] [PubMed]

35. Pino, E.; Campos, A.M.; Lopez-Alarcon, C.; Aspee, A.; Lissi, E. Free radical scavenging capacity of hydroxycinnamic acids and related compounds. J. Phys. Org. Chem. 2006, 19, 759-764. [CrossRef]

36. Amic, D.; Lucic, B. Reliability of bond dissociation enthalpy calculated by the pm 6 method and experimental teac values in antiradical qsar of flavonoids. Bioorg. Med. Chem. 2010, 18, 28-35. [CrossRef] [PubMed]

37. Zhang, H.-Y.; Wang, L.-F. Theoretical elucidation of structure-activity relationship for coumarins to scavenge peroxyl radical. J. Mol. Struct.Theochem 2004, 673, 199-202. [CrossRef]

38. Saito, M.; Sakagami, H.; Fujisawa, S. Cytotoxicity and apoptosis induction by butylated hydroxyanisole (bha) and butylated hydroxytoluene (bht). Anticancer Res. 2003, 23, 4693-4701. [PubMed]

39. Choe, E.; Min, D.B. Mechanisms of antioxidants in the oxidation of foods. Compr. Rev. Food Sci. Food Saf. 2009, 8, 345-358. [CrossRef]

40. Natella, F.; Nardini, M.; Di Felice, M.; Scaccini, C. Benzoic and cinnamic acid derivatives as antioxidants: Structure-activity relation. J. Agric. Food Chem. 1999, 47, 1453-1459. [CrossRef] [PubMed]

41. Musialik, M.; Kuzmicz, R.; Pawlowski, T.S.; Litwinienko, G. Acidity of hydroxyl groups: An overlooked influence on antiradical properties of flavonoids. J. Org. Chem. 2009, 74, 2699-2709. [CrossRef] [PubMed]

42. Hudson, B.J.F.; Lewis, J.I. Polyhydroxy flavonoid antioxidants for edible oils: Structural criteria for activity. Food Chem. 1983, 10, 47-55. [CrossRef]

43. Bors, W.; Heller, W.; Michel, C.; Saran, M. Flavonoids as antioxidants: Determination of radical-scavenging efficiencies. Methods Enzymol. 1990, 186, 343-355. [PubMed]

44. Garcia Aranzazu, M.; Ruiz-Mendez, V.; Romero, C.; Brenes, M. Effect of refining on the phenolic composition of crude olive oils. J. Am. Oil Chem. Soc. 2006, 83, 159-164. [CrossRef]

45. Hsu, D.-Z.; Chu, P.-Y.; Chandrasekaran, V.R.M.; Liu, M.-Y. Sesame lignan sesamol protects against aspirin-induced gastric mucosal damage in rats. J. Funct. Foods 2009, 1, 349-355. [CrossRef] 
46. Erkan, N.; Ayranci, G.; Ayranci, E. Antioxidant activities of rosemary (Rosmarinus officinalis L.) extract, blackseed (Nigella sativa L.) essential oil, carnosic acid, rosmarinic acid and sesamol. Food Chem. 2008, 110, 76-82. [CrossRef] [PubMed]

47. Guitard, R.; Paul, J.F.; Nardello, V.; Aubry, J.M. Myricetin, rosmarinic and carnosic acid as superior natural antioxidant alternatives to a-tocopherol for the preservation of omega-3 oils. Food Chem. 2016, submitted for publication. [CrossRef]

48. Beghdad, M.C.; Benammar, C.; Bensalah, F.; Sabri, F.-Z.; Belarbi, M.; Chemat, F. Antioxidant activity, phenolic and flavonoid content in leaves, flowers, stems and seeds of mallow (Malva sylvestris L.) from north western of algeria. Afr. J. Biotechnol. 2014, 13, 486-491.

49. Brand-Williams, W.; Cuvelier, M.E.; Berset, C. Use of a free radical method to evaluate antioxidant activity. Food Sci. Technol. 1995, 28, 25-30. [CrossRef]

50. Antolovich, M.; Prenzler, P.D.; Patsalides, E.; McDonald, S.; Robards, K. Methods for testing antioxidant activity. Analyst 2002, 127, 183-198. [CrossRef] [PubMed]

51. Huang, D.; Ou, B.; Prior, R.L. The chemistry behind antioxidant capacity assays. J. Agric. Food Chem. 2005, 53, 1841-1856. [CrossRef] [PubMed]

52. Mishra, K.; Ojha, H.; Chaudhury, N.K. Estimation of antiradical properties of antioxidants using DPPH[rad] assay: A critical review and results. Food Chem. 2012, 130, 1036-1043. [CrossRef]

53. Goupy, P.; Bautista-Ortin, A.-B.; Fulcrand, H.; Dangles, O. Antioxidant activity of wine pigments derived from anthocyanins: Hydrogen transfer reactions to the DPPH radical and inhibition of the heme-induced peroxidation of linoleic acid. J. Agric. Food Chem. 2009, 57, 5762-5770. [CrossRef] [PubMed]

54. Goupy, P.; Dufour, C.; Loonis, M.; Dangles, O. Quantitative kinetic analysis of hydrogen transfer reactions from dietary polyphenols to the dpph radical. J. Agric. Food Chem. 2003, 51, 615-622. [CrossRef] [PubMed]

55. Encinar, J.M.; Pardal, A.; Martinez, G. Transesterification of rapeseed oil in subcritical methanol conditions. Fuel Process. Technol. 2012, 94, 40-46. [CrossRef]

56. Lucarini, M.; Pedulli, G.F. Free radical intermediates in the inhibition of the autoxidation reaction. Chem. Soc. Rev. 2010, 39, 2106-2119. [CrossRef] [PubMed]

57. Brigati, G.; Lucarini, M.; Mugnaini, V.; Pedulli, G.F. Determination of the substituent effect on the o-h bond dissociation enthalpies of phenolic antioxidants by the epr radical equilibration technique. J. Org. Chem. 2002, 67, 4828-4832. [CrossRef] [PubMed]

58. Lucarini, M.; Pedrielli, P.; Pedulli, G.F.; Cabiddu, S.; Fattuoni, C. Bond dissociation energies of O-H bonds in substituted phenols from equilibration studies. J. Org. Chem. 1996, 61, 9259-9263. [CrossRef]

59. Foti, M.C.; Johnson, E.R.; Vinqvist, M.R.; Wright, J.S.; Barclay, L.R.C.; Ingold, K.U. Naphthalene diols: A new class of antioxidants intramolecular hydrogen bonding in catechols, naphthalene diols, and their aryloxyl radicals. J. Org. Chem. 2002, 67, 5190-5196. [CrossRef] [PubMed]

60. Li, J.; Bi, Y.; Liu, W.; Sun, S.; Liu, C.; Ma, S. Effect of acid value on tbhq and bht losses in heating oils: Identification of the esterification products of tbhq and free fatty acids. J. Am. Oil Chem. Soc. 2014, 91, 1763-1771. [CrossRef]

(c) 2016 by the authors; licensee MDPI, Basel, Switzerland. This article is an open access article distributed under the terms and conditions of the Creative Commons Attribution (CC-BY) license (http://creativecommons.org/licenses/by/4.0/). 